\title{
Numerical analysis of the strip crown inheritance in tandem cold rolling by a novel 3D multi-stand FE model
}

\author{
Lianjie $\mathrm{Li}^{1} \cdot \mathrm{Haibo} \mathrm{Xie}^{1} \cdot \mathrm{Tianwu} \mathrm{Liu}^{2} \cdot$ Mingshuai Huo ${ }^{1} \cdot{\mathrm{Xingsheng} \mathrm{Li}^{3} \cdot \mathrm{Xu} \mathrm{Liu^{2 }} \cdot \text { Enrui Wang }}^{4} \cdot$ Jianxin $\mathrm{Li}^{2}$. \\ Hongqiang Liu $^{2} \cdot$ Li Sun $^{2} \cdot$ Zhengyi Jiang $^{1}$
}

Received: 26 October 2021 / Accepted: 28 February 2022 / Published online: 7 March 2022

(c) The Author(s) 2022

\begin{abstract}
The strip shape inheritance model is widely applied to improve the strip shape quality in tandem cold rolling (TCR). However, the inheritance mechanism is still currently unclear. To bridge this gap, this paper presents a new numerical method for calculating the strip crown inheritance factor. In addition, the effects of the entry strip crown on exit strip crown and flatness were quantitatively analysed at each stand in the TCR using a novel three-dimensional (3D) multi-stand elasticplastic finite element (FE) model. The results show that the strip crown inheritance factor increases slowly from S1 (stand 1) to S3 (stand 3), while rising sharply from S3 to S5 (stand 5), reaching a peak value of $0.495 \mu \mathrm{m} / \mu \mathrm{m}$ at $\mathrm{S} 5$. This trend coincides with that of strip plastic rigidity, which verifies that the strip crown inheritance factor is dependent on the strip plastic rigidity. Furthermore, the variation of strip crown and flatness under different entry strip crowns from S1 to S5 is jointly influenced by the pass reduction and strip plastic rigidity. Moreover, the strip crown inheritance factor increases with the deformation resistance of the strip at both S1 and S5. These findings not only offer a fresh perspective to understand the mechanism of strip crown inheritance, but also provide an important basis for optimising the strip shape control in the TCR process.
\end{abstract}

Keywords Entry strip crown $\cdot$ Strip crown inheritance factor $\cdot$ 3D multi-stand FE model $\cdot$ Tandem cold rolling $\cdot$ Strip plastic rigidity

\section{Introduction}

Except a portion of hot-rolled strips used directly in the manufacturing field, the rest are used as raw material for cold rolling. The quality of hot-rolled strips plays an important role in the finished cold-rolled products, especially the strip shape. This is because the cold-rolled strip inherits the

\section{Zhengyi Jiang}

jiang@uow.edu.au

1 School of Mechanical, Materials, Mechatronic and Biomedical Engineering, Faculty of Engineering and Information Sciences, University of Wollongong, Wollongong, NSW 2522, Australia

2 HBIS Group Technology Research Institute, Shijiazhuang 050023, Hebei, People's Republic of China

3 Graduate School of Engineering, Osaka University, Osaka 565-0871, Japan

4 HBIS Group Hansteel Company, Handan 056015, Hebei, People's Republic of China strip shape from the incoming hot-rolled strip. This phenomenon has attracted the attention of many researchers in recent decades. Guo [1] studied the cascade effect of the incoming strip crown on the exit strip crown. The results showed that the exit strip crown increases with the incoming strip crown, and the incoming strip crown has little effect on the last stand, about 2.5\%. Park et al. [2] reported that the cold-strip crown values are linearly related to the hot-rolled strip values, but the degree of dependency varies with strip thickness. Zhang et al. [3] and Yu et al. [4] discovered that increasing the entry strip crown causes an increase in the exit strip crown and the edge drop in a universal crown control mill (UCM mill) and a 20-high Sendzimir mill, respectively. Ma et al. [5] carried out a numerical analysis about the influence of the hot-rolled strip profile on transverse thickness difference (TTD) of cold-rolled silicon steel, and found that the TTD of the cold-rolled strip has a nearly linear relationship with the $\mathrm{C}_{40}$ (crown at $40 \mathrm{~mm}$ from the strip edge) of the hot-rolled strip without wedge, while the TTD of cold-rolled strip increases nonlinearly with the $\mathrm{W}_{40}$ (wedge at $40 \mathrm{~mm}$ 
from the strip edge) at a certain $\mathrm{C}_{40}$. Using the same method, Wang et al. [6] also found that the TTD of cold-rolled strip increases with the $\mathrm{C}_{25}$ (crown at $25 \mathrm{~mm}$ from the strip edge) of the hot-rolled strip when the $\mathrm{C}_{40}$ remains constant and the ratio of $\mathrm{C}_{40}$ to $\mathrm{C}_{25}$ varies. Even though the quantitative analysis of the strip crown inheritance has been extensively conducted, to our knowledge, the underlying mechanism has not been determined up to now. Therefore, additional study is essential to elucidate the mechanism behind the strip crown inheritance.

Given the fact that the five-stand TCR mill features high speed and highly continual process, it is difficult to conduct massive experiments to measure the exact entry and exit strip cross-section profiles manually, especially at the interstand. Instead, the numerical method, like the finite element method (FEM), has been widely used to tackle complicated strip rolling problems. Zhou et al. [7] predicted the strip thickness profile in a four-high mill using the 2D variable element thickness FEM. Jiang et al. [8-10] simulated the cold rolling of the thin strip by the 3D rigid-plastic FEM. Sun et al. [11] calculated the roll deformation of a six-high mill using a 3D symmetrical FE model. Aljabri et al. [12] analysed the effect of work roll crossing on the strip crown employing a 3D symmetrical FE model. Wang et al. [13-15] systematically studied the effects of work roll bending (WRB), intermediate roll bending (IRB), and intermediate roll shifting (IRS) on the strip crown and flatness in a UCM mill using a 3D elastic-plastic FE model. Cao et al. [16] applied the FEM to design new roll contours to improve the edge drop and strip crown in four-high and sixhigh tandem cold mills. Zamanian et al. [17] evaluated the strip crown control performance of a new uniform thickness control mill using a 3D symmetrical elastic-plastic FE model. Wang et al. [18] explored the effects of IRS on strip edge drop in a six-high tandem cold mill employing a 3D elastic-plastic FE model based on the explicit method. Wang et al. [19] calculated the strip cross-section profile and flatness under different IRS values and strip widths in a six-high SmartCrown mill using a 3D elastic-plastic FE model. However, the above FE models for cold strip rolling were limited to an individual stand, the effect of neighbouring stands on the strip shape was neglected, namely, the strip crown inheritance had not been taken into account. Linghu et al. [20] developed a 3D FE model for multi-pass rolling in a 6-high continuously variable crown (CVC) cold mill, but data transfer between the neighbouring stands like the strip crown inheritance was not clear. In our previous study [21], a novel 3D multi-stand FE model for the TCR was proposed considering the work hardening effect, thus making it available for investigating the strip crown inheritance.

Here in this paper is reported, for the first time, the study of strip crown inheritance in the TCR process employing a novel 3D multi-stand FE model. First, the effects of the entry strip crown on exit strip crown and flatness from S1 to S5 were quantitatively studied; second, the effects of the entry strip crown on the loaded roll gap profile, deflection, and flattening deformation of work roll (WR) were analysed; third, the quantitative relationship between the strip crown inheritance factor and strip plastic rigidity was determined; next, the formation mechanism of the strip crown and flatness under different entry strip crowns was revealed; finally, the relationship between the strip crown inheritance factor and the deformation resistance of the strip at both S1 and S5 was disclosed. Not only does this work provide a new method for calculating the strip crown inheritance factor, but it also offers new insight into the strip crown inheritance.

\section{3D multi-stand FE model for TCR}

In this section, a novel 3D multi-stand elastic-plastic FE model for the TCR was built up based on the MSC.Marc software using the segmentation modelling strategy, data transfer technologies, and element remesh technology. Furthermore, the rolling experiment was conducted on a 2180 $\mathrm{mm}$ TCR production line to validate the established FE model in terms of the strip cross-section profile and rolling force.

\subsection{Modelling strategy}

Figure 1a shows a $2180 \mathrm{~mm}$ TCR mill, including five sixhigh mills. If they are modelled in a FE model, there will be millions of elements, resulting in the tiny calculation step and high computation costs. Besides, the strip elements will distort severely because of significant elongation caused by heavy reduction. To solve the aforementioned issue, the TCR mill was divided into five distinct stands designated S1, S2, S3, S4, and S5, each of which was modelled as an individual FE model, called the segmentation modelling strategy [21], as illustrated in Fig. 1b. In order to integrate each stand into one complete model, the data transfer technologies were developed to transfer data between the neighbouring stands, including transferring the strip cross-section profile and the total equivalent plastic strain (TEPS) of the strip. Moreover, the five individual FE models were calculated one by one, and the corresponding calculation flow chart is depicted in Fig. 2.

\subsection{Data transfer technologies}

After one single FE model was calculated, the strip crosssection profile and TEPS need to be transferred to the next single FE model. The corresponding data transfer technologies [21] are illustrated in detail as follows. 
Fig. 1 a $2180 \mathrm{~mm}$ TCR mill b 3D multi-stand FE model
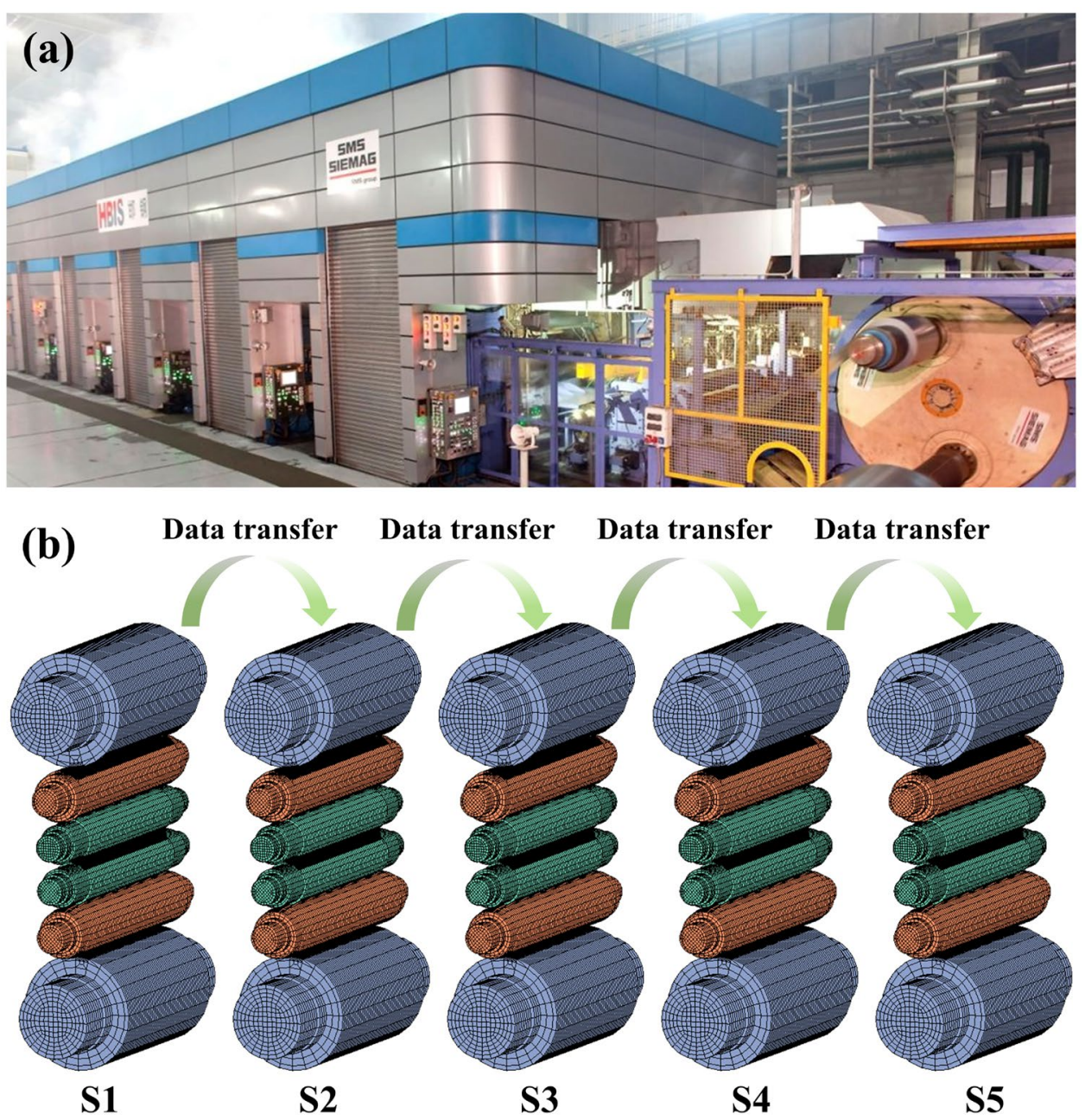

Data transfer from model S1 to S2 is taken as an example to describe the transferring process. Figure 3 gives the calculation flow chart for data transfer of strip cross-section

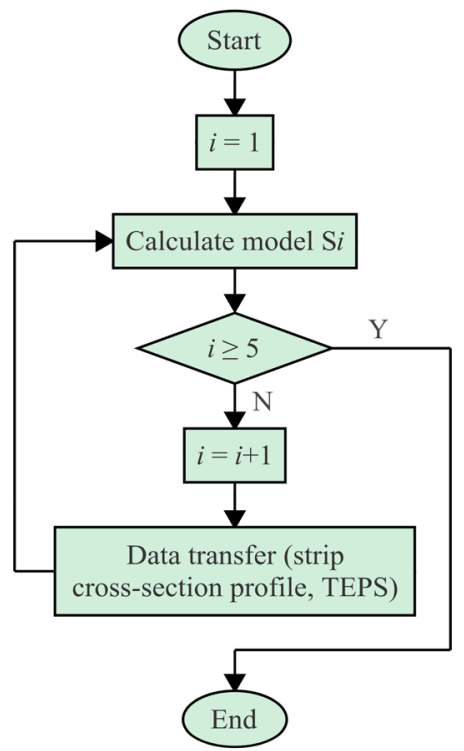

Fig. 2 Calculation flow chart of the multi-stand FE model profile. As seen in Fig. 3, first, open the last step of model $\mathrm{S} 1$ after it was calculated; second, extract node coordinates of the cross-section in the middle of the strip and then export these coordinates to a new data file; next, assign the node coordinates to model S2 as key nodes, which can be used to generate the $2 \mathrm{D}$ plane elements, i.e. the initial cross-section profile. After that, the plane elements were expanded to a 3D strip (see Fig. 4), during which the elements were remeshed to maintain regular. All the operations were carried out by Mentat commands (They are used to replay the manual operation in Mentat session, stored in a procedure file called mentat.proc).

Figure 5 shows the calculation flow chart for data transfer of the TEPS. It includes three steps. As shown in Fig. 5, the first step is to open the last step of model S1 after it has been calculated; the second step is to extract the TEPS at each integration point of strip elements and then export the TEPS to a new data file by subroutine ELEVAR; following that, the last step is to assign the TEPS to model S2 according to the element number by subroutine INITPL. In this way, the TEPS can be transferred from model S1 to S2, as displayed in Fig. 6. From Fig. 6, it can be seen that the distribution of 


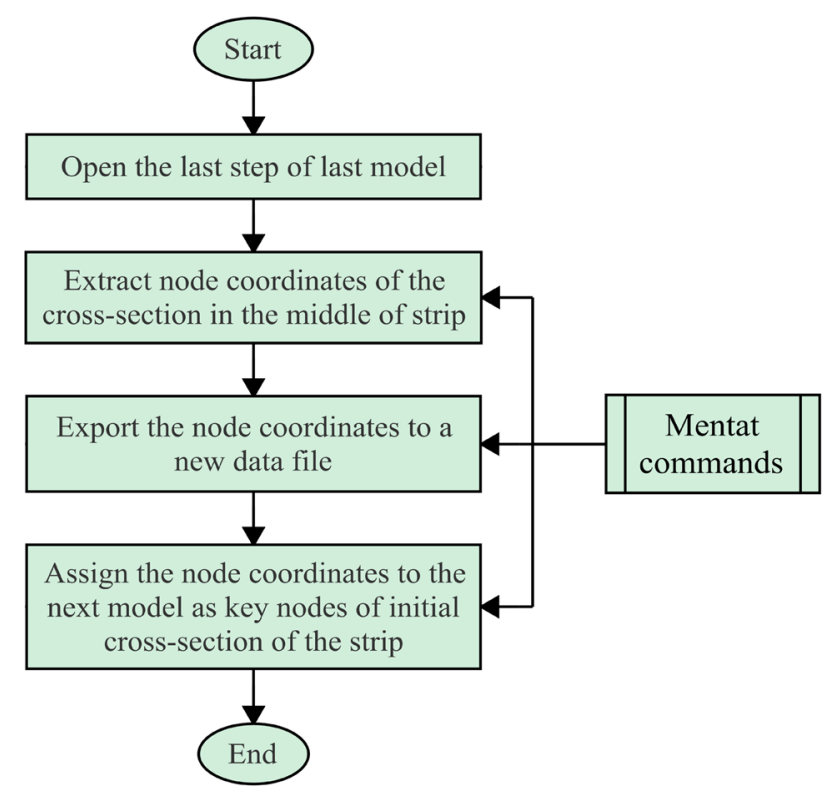

Fig. 3 Calculation flow chart for data transfer of strip cross-section profile

TEPS at the start of model S2 is consistent with that at the end of model S1. Figure 7 presents the TEPS contour of the rolled strip from $\mathrm{S} 1$ to $\mathrm{S} 5$. It can be observed that the TEPS

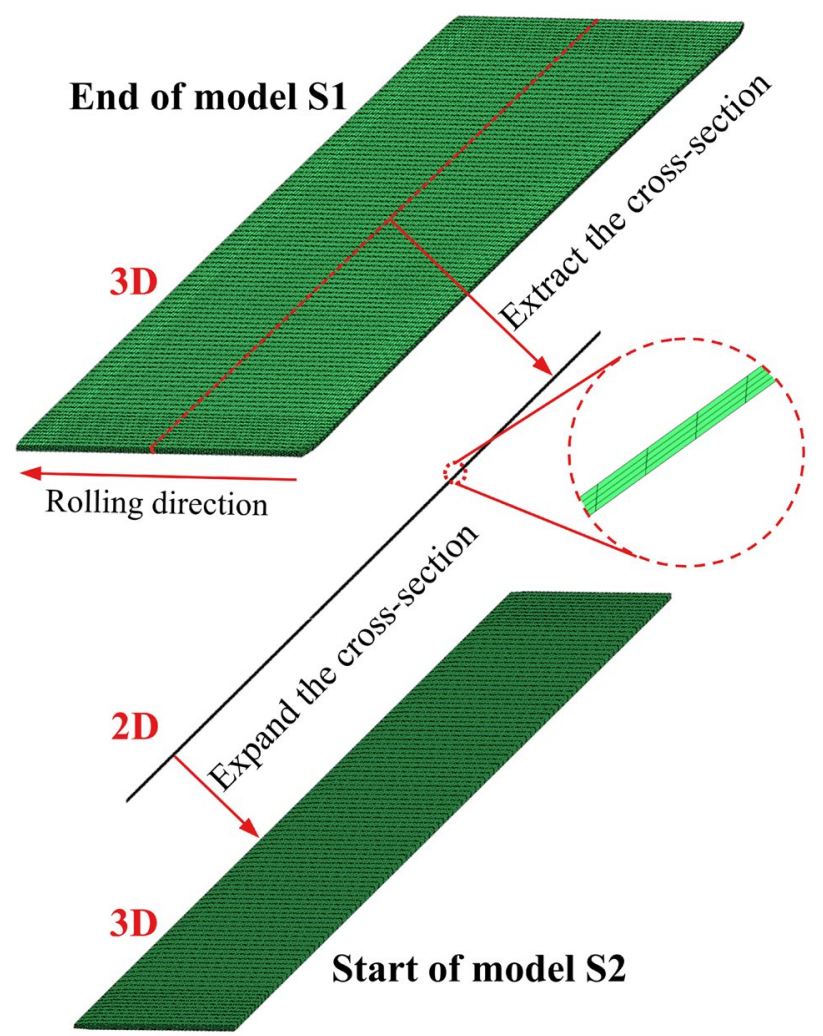

Fig. 4 Sketch map of data transfer of strip cross-section profile

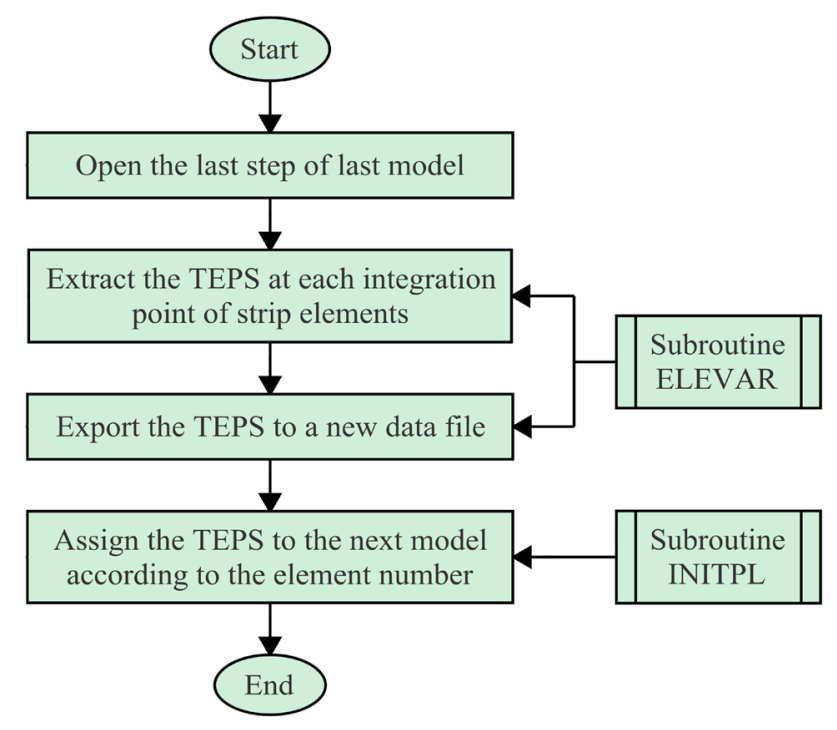

Fig. 5 Calculation flow chart for data transfer of the TEPS

increases continuously from S1 to S5; this is to say, the work hardening effect caused by plastic strain accumulation has been realised through the data transfer of the TEPS.

\subsection{Material properties}

The strip material used in this model was one type of highstrength steel DC01. The strip and rolls are classified as elastic-plastic body and elastic bodies, respectively, with

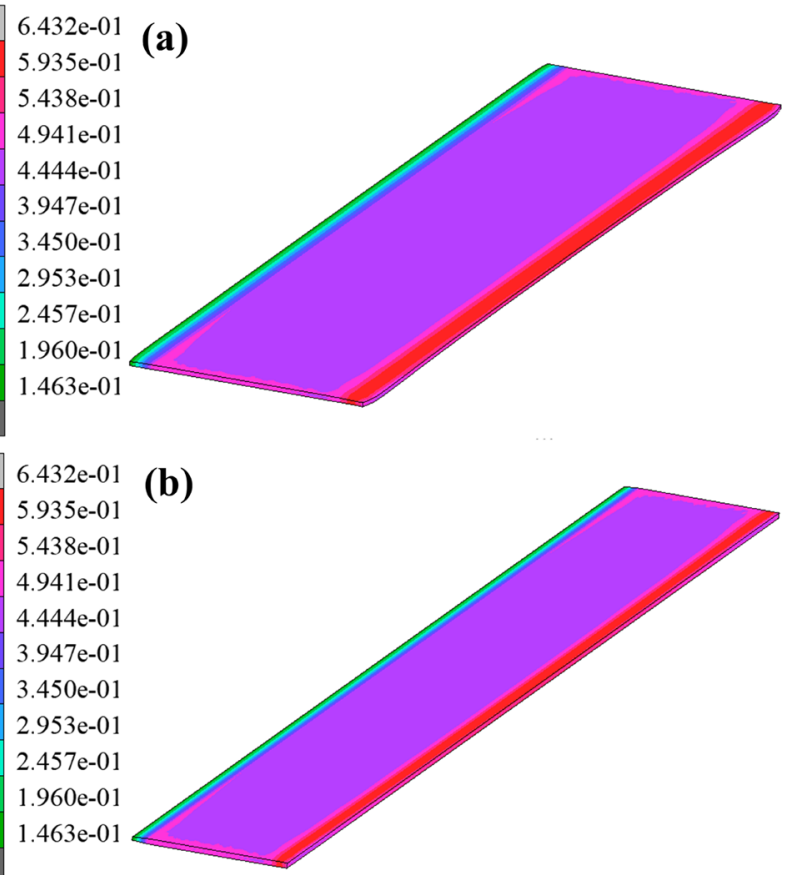

Fig. 6 TEPS contour: $\mathbf{a}$ at the end of S1 $\mathbf{b}$ at the start of S2 

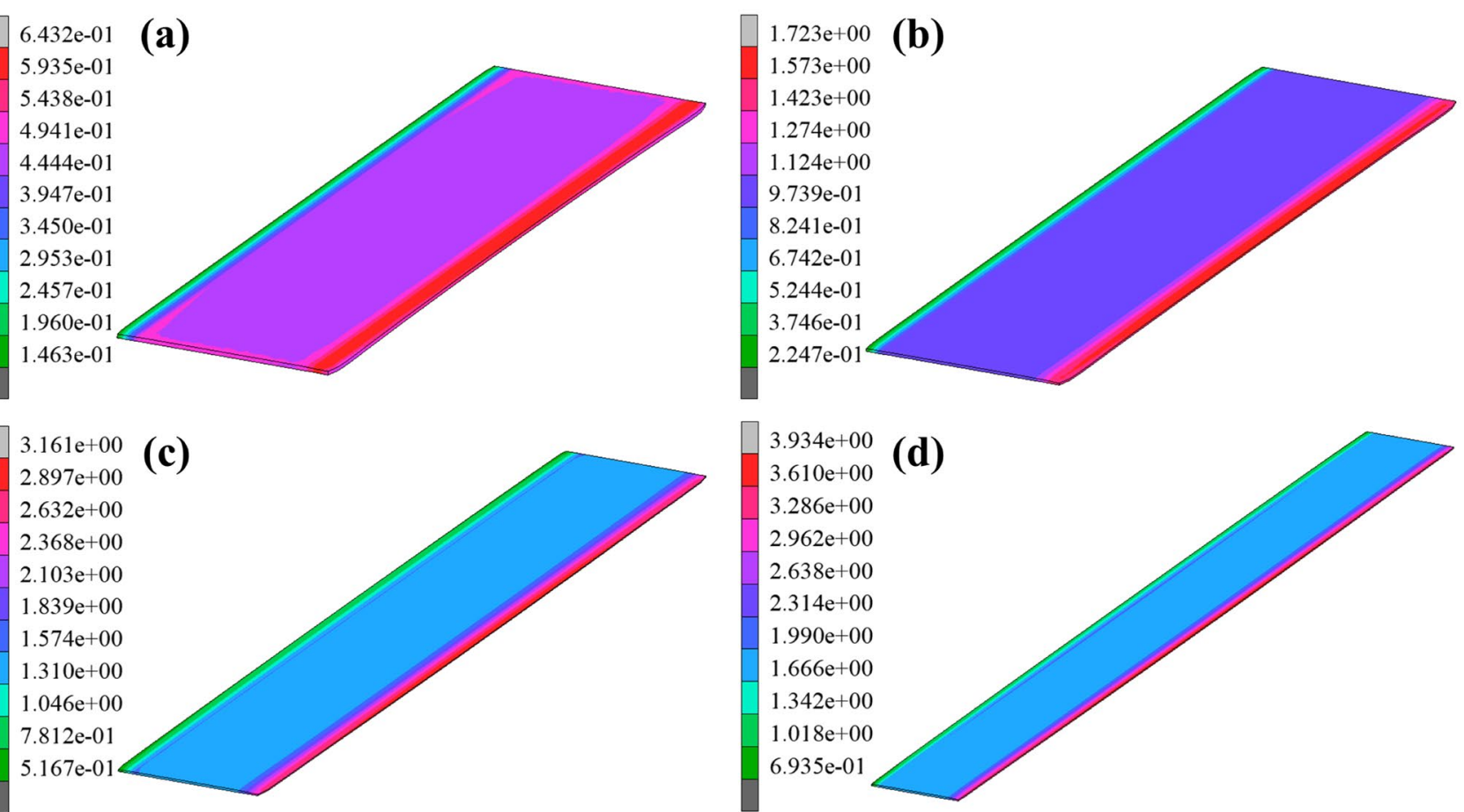

$3.934 \mathrm{e}+00$

$3.610 \mathrm{e}+00$

$3.286 \mathrm{e}+00$

$2.962 \mathrm{e}+00$

$2.638 \mathrm{e}+00$

$2.314 \mathrm{e}+00$

$1.990 \mathrm{e}+00$

$1.666 \mathrm{e}+00$

$1.342 \mathrm{e}+00$

$1.018 \mathrm{e}+00$

$6.935 \mathrm{e}-01$
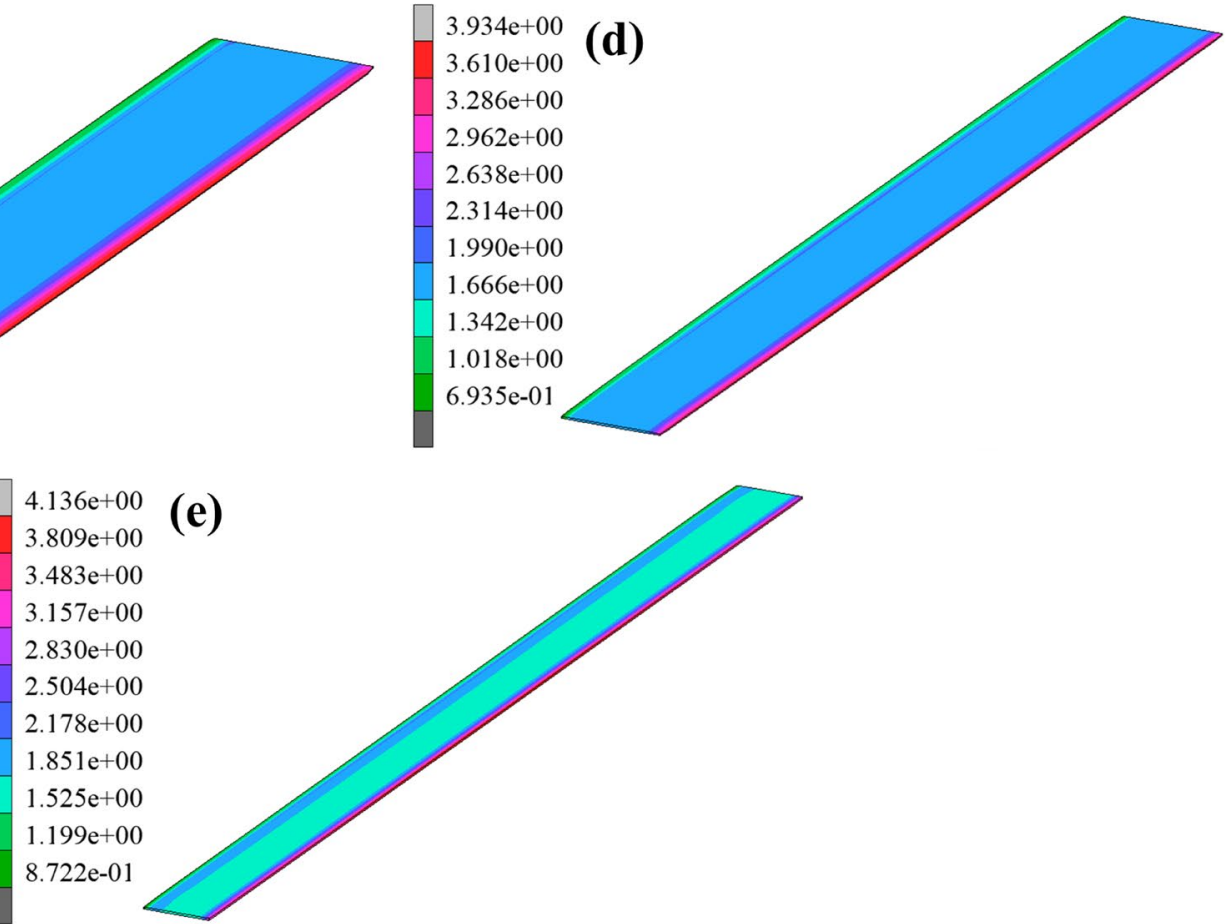

Fig. 7 TEPS contour of the rolled strip: a S1 b S2 c S3 d S4 e S5

physical properties summarised in Table 1. Taking into account the work hardening effect, rolling-tension tests were carried out to determine the static deformation resistance of the strip, which is expressed in Eq. (1) [21]. During the TCR process, the average unit rolling pressure remains steady or even declines somewhat when the rolling speed increases [22]. This might attribute to a decrease in deformation resistance caused by a rise in strip temperature, or to a drop in external friction caused by a change in lubrication conditions

Table 1 Material physical parameters of rolls and strip

\begin{tabular}{llll}
\hline Item & Density $\left(\mathrm{kg} / \mathrm{m}^{3}\right)$ & Poisson's ratio & $\begin{array}{l}\text { Young's } \\
\text { modulus } \\
(\mathrm{GPa})\end{array}$ \\
\hline Rolls & 7860 & 0.3 & 210 \\
Strip & 7850 & 0.3 & 211 \\
\hline
\end{tabular}

in high-speed rolling [22]. Thereby, the influence of strain rate on deformation resistance (i.e. the influence of strain rate on the rolling force) was ignored here, and the static deformation resistance was employed in this FE model.

$\sigma_{s}=365.54+208.1 \varepsilon^{0.381}$

$\varepsilon=\ln \frac{H}{h}$

where $\sigma_{s}, \varepsilon, H$, and $\mathrm{h}$ are the deformation resistance, true strain, entry thickness, and exit thickness, respectively.

\subsection{Governing equation}

Marc is a stiffness-based programme that focuses on force-displacement interactions. In a linear elastic system, 
force and displacement are connected through the constant stiffness; the governing equation can be written as Eq. (3) [23].

$\boldsymbol{K u}=\boldsymbol{F}$

where $\boldsymbol{K}$ denotes the stiffness matrix, which is expressed as Eq. (4); $\boldsymbol{u}$ denotes the nodal displacement vector; and $\boldsymbol{F}$ denotes the force vector.

$\boldsymbol{K}=\int_{0}^{\Omega} \boldsymbol{B}^{T} \boldsymbol{D} \boldsymbol{B} d \Omega$

where $\boldsymbol{B}$ is the strain-displacement matrix, and $\boldsymbol{D}$ is the elastic matrix.

In a nonlinear stress analysis, Marc analyses incrementally and describes the governing equation as Eq. (5) in terms of the incremental displacement vector $\delta \boldsymbol{u}$ and the incremental force vector $\delta \boldsymbol{F}$ [23].

$\boldsymbol{K} \delta \boldsymbol{u}=\delta \boldsymbol{F}$

For the cold rolling analysis, boundary conditions can divide into two types: the displacement boundary conditions and force boundary conditions. Equation (6) can be used to describe the displacement boundary conditions [24]. The force boundary conditions are comprised of the point force, surface force, and load surface; hence, the $\boldsymbol{F}$ can be defined as Eq. (7) [23].

$\boldsymbol{u}=\overline{\boldsymbol{u}}(x, t)$

where $\overline{\boldsymbol{u}}$ denotes the specified quantity, $x$ denotes the loaded boundary, and $t$ denotes the time.

$\boldsymbol{F}=\boldsymbol{F}_{\text {point }}+\boldsymbol{F}_{\text {surface }}+\boldsymbol{F}_{\text {body }}+\boldsymbol{F}^{*}$

where $\boldsymbol{F}_{\text {point }}, \boldsymbol{F}_{\text {surface }}$, and $\boldsymbol{F}_{\text {body }}$ represent the point load vector, surface load vector, and body load vector, respectively; $\boldsymbol{F}^{*}$ denotes the other load vectors like initial stress.

\subsection{Simulation conditions}

In this model, the roll contours of WR, intermediate roll (IMR), and back-up roll (BR) were modelled by discrete points, which were conventional contour, CVC [25], and Anti-CVC, respectively. Moreover, in order to ensure the accuracy of calculation, the full Newton-Raphson method for the implicit algorithm was applied to solve the nonlinear equilibrium equations. The Coulomb bilinear friction model was adapted to define the rolling contact behaviour. The entry and exit tension stresses (with opposite directions) were exerted on the strip head and tail surfaces, respectively, as shown in Fig. 8. Besides, the entry strip cross-section profile at $\mathrm{S} 1$ was assumed using a quadratic curve, with the crown of $0.05 \mathrm{~mm}$, as displayed in Fig. 9. In addition, the

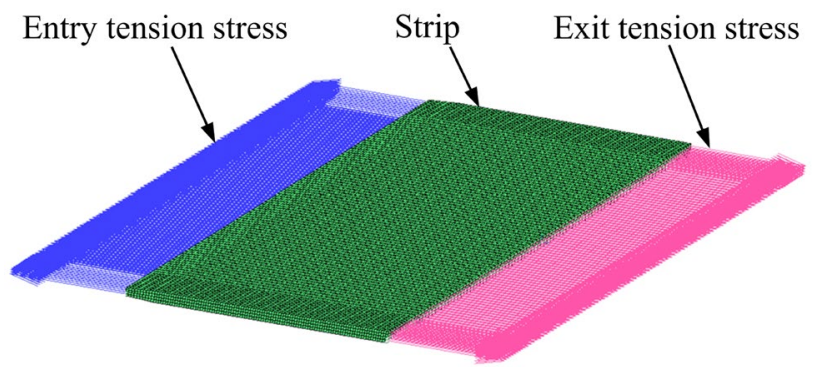

Fig. 8 Entry and exit tension stresses in a single FE model

elements used in the model were eight-node hexahedral elements, with a total element number of 214,808 for a single FE model. The other parameters are listed in Table 2. The calculation was performed on a workstation equipped with an Intel Xeon E5-2667 v3 processor and 64 GB of RAM.

\subsection{Validation of the 3D multi-stand FE model}

Industrial experiments in a $2180 \mathrm{~mm}$ TCR mill were conducted to validate the accuracy of the developed 3D multistand FE model. The experimental rolling force is compared with the simulated one for each stand from S1 to S5 in Fig. 10. As illustrated in Fig. 10, the simulated rolling force shows a declining trend from S1 to S5 due to a decrease in pass reduction [26]. Besides, the simulated rolling force is close to the experimental value, with a relative error of less than 5\%. Figure 11 shows the simulated and experimental exit strip cross-section profile from S1 to S5 [18]. As shown in Fig. 11, it is obvious that the simulated strip crown (the difference between the strip centre and edge thickness) decreases significantly from $\mathrm{S} 1$ to $\mathrm{S} 5$, which is consistent with the practical experience. Moreover, the simulated values agree with the experimental ones in the majority of

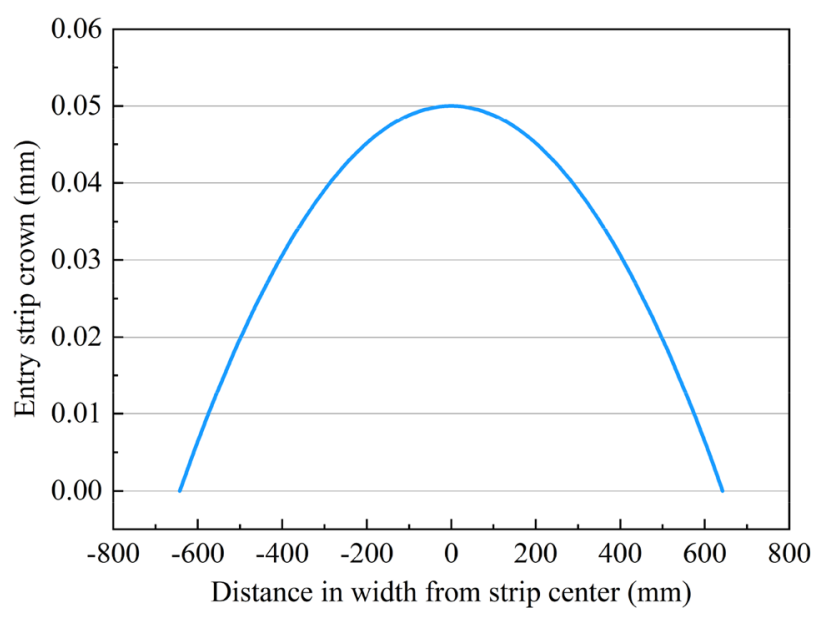

Fig. 9 Entry strip cross-section profile 
Table 2 Simulation conditions

\begin{tabular}{llllll}
\hline Parameters & S1 & S2 & S3 & S4 & S5 \\
\hline Diameter of WR (mm) & 520 & 520 & 520 & 520 & 520 \\
Barrel length of WR (mm) & 2,180 & 2,180 & 2,180 & 2,180 & 2,180 \\
Distance between bearings of WR (mm) & 3,400 & 3,400 & 3,400 & 3,400 & 3,400 \\
Diameter of IMR (mm) & 610 & 610 & 610 & 610 & 610 \\
Barrel length of IMR (mm) & 2,580 & 2,580 & 2,580 & 2,580 & 2,580 \\
Distance between bearings of IMR (mm) & 3,440 & 3,440 & 3,440 & 3,440 & 3,440 \\
Diameter of BR (mm) & 1,380 & 1,380 & 1,380 & 1,380 & 1,380 \\
Barrel length of BR (mm) & 2,180 & 2,180 & 2,180 & 2,180 & 2,180 \\
Distance between bearings of BR (mm) & 3,400 & 3,400 & 3,400 & 3,400 & 3,400 \\
Rolling velocity (m/s) & 3.5 & 5.0 & 7.5 & 10.5 & 14.5 \\
Intermediate roll shifting (mm) & 17 & 18 & 8 & 46 & 25 \\
Intermediate roll bending (kN) & 280 & 273 & 302 & 323 & 225 \\
Work roll bending (kN) & 271 & 270 & 309 & 328 & 220 \\
Entry thickness (mm) & 4.409 & 3.013 & 1.927 & 1.343 & 1.057 \\
Exit thickness (mm) & 3.013 & 1.927 & 1.343 & 1.057 & 1.000 \\
Reduction ratio (\%) & 31.6 & 36.0 & 30.3 & 21.3 & 5.4 \\
Entry tension (kN) & 255 & 465 & 330 & 245 & 195 \\
Exit tension (kN) & 465 & 330 & 245 & 195 & 40 \\
Friction coefficient & 0.05 & 0.05 & 0.05 & 0.05 & 0.05 \\
Entry strip width (mm) & 1,285 & - & - & - & - \\
\hline
\end{tabular}

regions at S5. This demonstrates the accuracy of the developed multi-stand FE model.

\section{Evaluation index of strip shape}

In practice, strip shape includes two parts: strip cross-section profile and strip flatness. The cross-section profile reflects the geometric features along the strip width direction, while

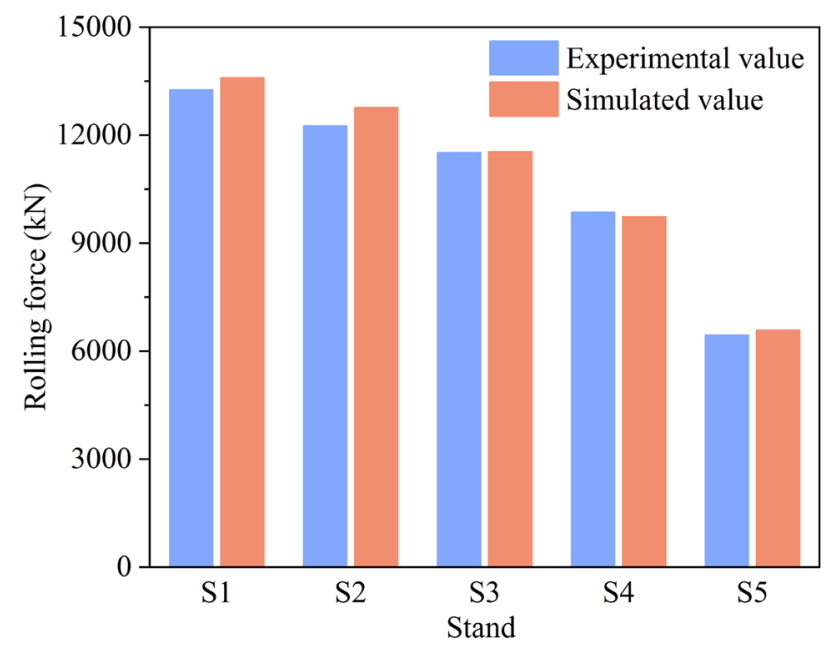

Fig. 10 Comparison between the experimental and simulated rolling forces from S1 to S5 the flatness reflects the geometric characteristics along the strip rolling direction. They are evaluated by various indexes below.

\subsection{Strip cross-section profile}

The indexes of strip cross-section profile (see Fig. 12) consist of crown, edge drop, wedge, and local high-spot. Specifically, strip crown $C_{40}$, edge drop $E_{40}$, and wedge $W_{40}$, expressed as Eqs. (8)-(10) below, are generally used as feature values to evaluate the strip cross-section profile.

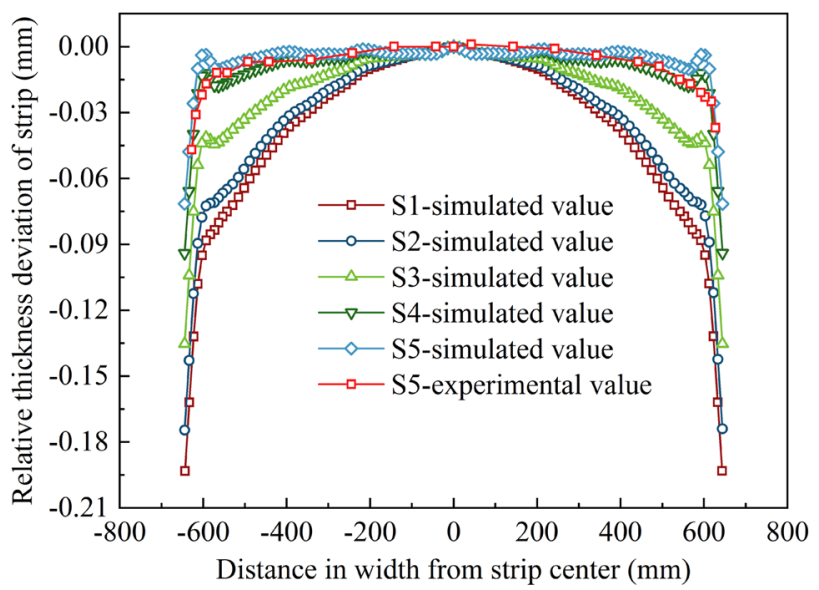

Fig. 11 Comparison among exit strip cross-section profiles from S1 to S5 
Fig. 12 Sketch map of strip cross-section profile

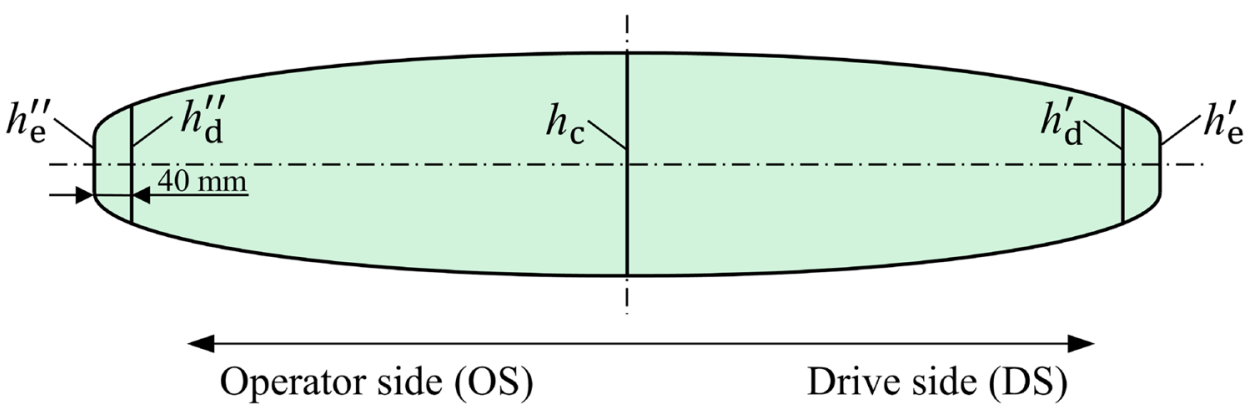

$C_{40}=\frac{\left(h_{c}-h_{d}^{\prime}\right)+\left(h_{c}-h_{d}^{\prime \prime}\right)}{2}$

$E_{40}=\frac{\left(h_{d}^{\prime}-h_{e}^{\prime}\right)+\left(h_{d}^{\prime \prime}-h_{e}^{\prime \prime}\right)}{2}$

$W_{40}=h_{d}^{\prime \prime}-h_{d}^{\prime}$

where $C_{40}, E_{40}$, and $W_{40}$ denote the strip crown, edge drop, and wedge at $40 \mathrm{~mm}$ from the strop edge, respectively; $h_{c}$ denotes the centre thickness; $h_{d}^{\prime}$ and $h_{d}^{\prime \prime}$ denote the thickness at $40 \mathrm{~mm}$ from the edge (DS side and OS side separately); and $h_{e}^{\prime}$ and $h_{e}^{\prime \prime}$ denote the edge thickness at the DS side and OS side separately.

\subsection{Strip flatness}

The flatness defect occurs during strip rolling as a result of the strip fibres' non-uniform elongation, which includes centre wave, edge wave, quarter wave, and edge-centre coupled wave [27], as shown in Fig. 13. When the rolled strip sample is cut into lots of narrow fibres longitudinally, the fibres contract or stretch elastically as the residual stress is released. In this way,
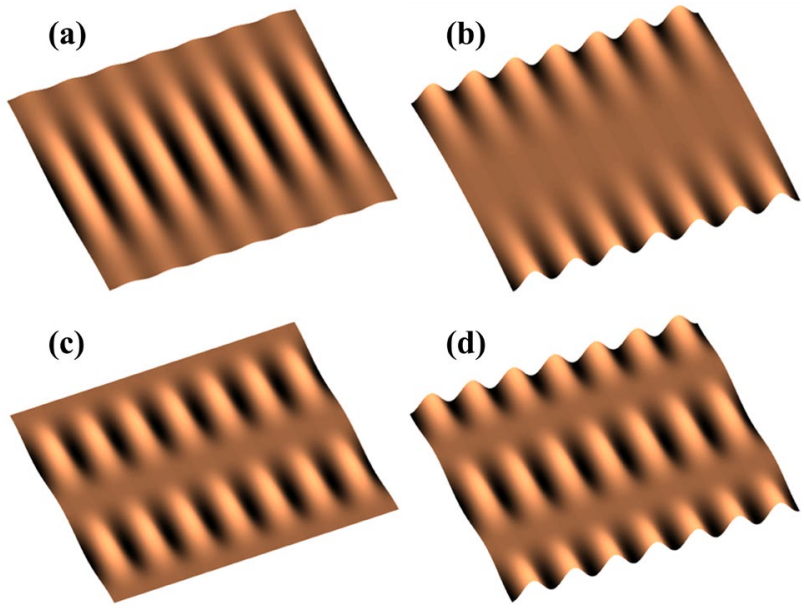

Fig. 13 The flatness types: a centre wave b edge wave c quarter wave $\mathbf{d}$ edge-centre coupled wave the flatness can be expressed by the length difference of these fibres as Eq. (11) [27].

$I(x)=\frac{L(x)-\bar{L}}{\bar{L}} \times 10^{5}$

where $I(x)$ is the flatness at location $x$ (the unit is IU); $L(x)$ is the length of strip fibre at location $x$; and $\bar{L}$ is the average length of the strip fibres.

A quartic polynomial can be used to fit the flatness curve as Eq. (12), which can also be rewritten using Chebyshev polynomials [28, 29] as Eq. (13).

$I(x)=a_{0}+a_{1} x+a_{2} x^{2}+a_{3} x^{3}+a_{4} x^{5}$

where $a_{0}, a_{1}, a_{2}, a_{3}$, and $a_{4}$ are the coefficients; $x$ is the normalised width, from -1 to 1 .

$$
\begin{aligned}
I(x) & =-\frac{1}{2} x F l t_{1}-\frac{1}{2}\left(2 x^{2}-1\right) F l t_{2} \\
& -\frac{1}{2}\left(4 x^{3}-3 x\right) F l t s_{3}-\frac{1}{2}\left(8 x^{4}-8 x^{2}+1\right) F l t_{4}+\Delta
\end{aligned}
$$

where $F l t_{1}, F l t_{2}, F l t_{3}$, and $F l t_{4}$ denote the first flatness, quadratic flatness, cubic flatness, and quartic flatness, respectively, which can be expressed by Eqs. (14)-(17); $\Delta$ denotes the error.

$F l t_{1}=-2 a_{1}-\frac{3}{2} a_{3}$

$F l t_{2}=-a_{2}-a_{4}$

$F t_{3}=-\frac{1}{2} a_{3}$

$F l t_{4}=-\frac{1}{4} a_{4}$

The asymmetrical shape control means (like roll tilting) are not considered in this work, and thus the $F l t_{1}$ and $F l t_{3}$ are neglected, while the $\mathrm{Flt}_{2}$ and $\mathrm{Flt}_{4}$ are focused on evaluating the flatness. It can be deduced from Eqs. (13), (15), and (17) that: when $F l t_{2}>0$, it is the centre wave; whereas when $F l t_{2}<0$, it is the edge wave; when $F l t_{4}>0$, it is the quarter 
wave; whereas when $\mathrm{Flt}_{4}<0$, it is the edge-centre coupled wave. Therefore, the wave types can be classified into four different assemblies according to the value of $\mathrm{Flt}_{2}$ and $\mathrm{Flt}_{4}$, as displayed in Fig. 14, which makes it easy to determine the wave type.

\section{Entry strip crown}

To study the effects of entry strip crown on exit strip crown and flatness, five different entry strip cross-section profiles were selected to develop the FE model from S1 to S4, while seven different entry strip cross-section profiles were chosen for S5, as shown in Fig. 15. The corresponding entry strip crown $C_{40}^{E n}$ are summarised in Table 3. During the FE modelling, the other parameters were kept the same in Table 2 except the entry strip cross-section profile.

\section{Results and discussions}

\subsection{Effects of entry strip crown on exit strip crown}

Figure 16 presents the relative thickness deviation (RTD) of the strip under different entry strip crowns from S1 to S5. It can be seen from Fig. 16 that the distribution of RTD along the strip width direction is non-homogeneous; that is, the RTD at the strip edge is much larger than that in the central strip region, forming the so-called edge drop. The RTD along the strip width direction shows a 'hill' shape

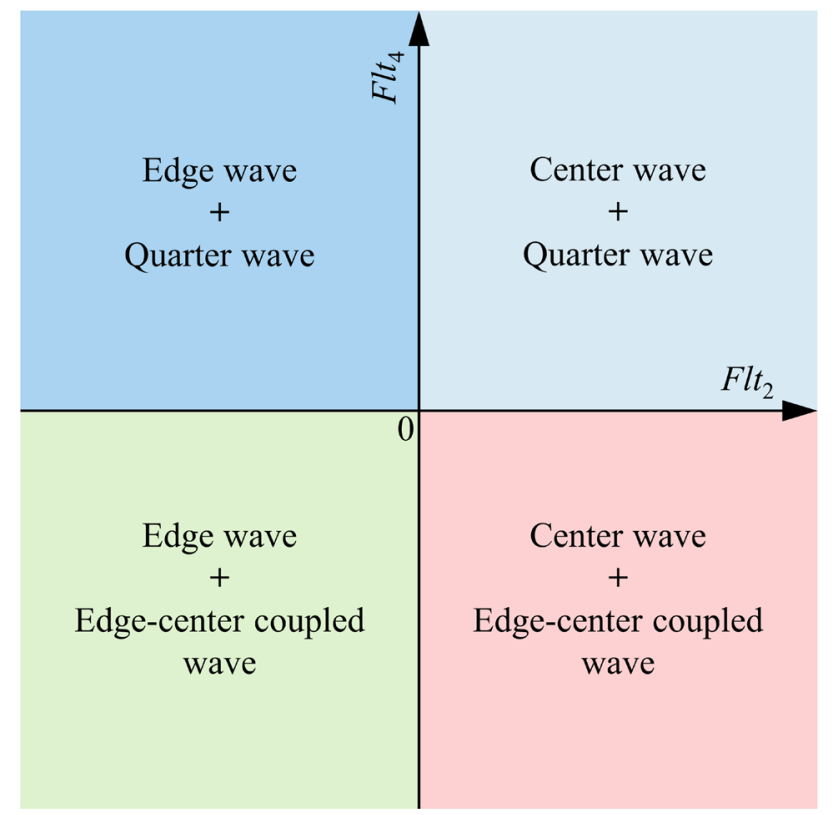

Fig. 14 Four different wave assemblies from $\mathrm{S} 1$ to $\mathrm{S} 3$, and the shape changes a little when the entry strip crown varies. By contrast, as for S4 and S5, the shape of RTD changes from a 'hill' to a 'valley' when the entry strip crown varies from positive to negative. Moreover, the RTD shows a decreasing trend on the whole from S1 to S5.

Figure 17 exhibits the efficiency curves of the entry strip crown on the exit strip crown from S1 to S5. It is apparent from Fig. 17 that all the curves show a linearly decreasing trend when the entry strip crown decreases from positive to negative, but with different slopes. To be specific, when the entry strip crown $C_{40}^{E n}$ decreases from 116.4 to $-145.7 \mu \mathrm{m}$, the exit strip crown $C_{40}^{E x}$ of $\mathrm{S} 1$ decreases from 96.8 to $89.8 \mu \mathrm{m}$, and the $C_{40}^{E x}$ of $\mathrm{S} 2$ declines gradually from 78.0 to $70.1 \mu \mathrm{m}$. Similarly, the $C_{40}^{E x}$ of S3 shows a steady decrease from 48.7 to $32.7 \mu \mathrm{m}$ when the $C_{40}^{E n}$ decreases from 119.7 to $-115.1 \mu \mathrm{m}$. In comparison, when it comes to S4 and S5, the $C_{40}^{E x}$ evolves from positive to negative with decreasing the $C_{40}^{E n}$. More precisely, the $C_{40}^{E x}$ of $\mathrm{S} 4$ sees a big decline from 27.2 to $-12.9 \mu \mathrm{m}$ when the $C_{40}^{E n}$ decreases from 106.7 to $-112.7 \mu \mathrm{m}$, whereas the $C_{40}^{E x}$ of S5 undergoes the steep drop from 25.6 to $-41.5 \mu \mathrm{m}$ when the $C_{40}^{E n}$ decreases from 59.9 to $-75.2 \mu \mathrm{m}$.

In order to quantitatively study the effect of entry strip crown on exit strip crown, the strip crown inheritance factor $\eta$ is introduced by Eq. (18).

$\eta=\frac{\Delta C_{40}^{E x}}{\Delta C_{40}^{E n}}$

where $\Delta C_{40}^{E x}$ is the variation of $C_{40}^{E x}$, and $\Delta C_{40}^{E n}$ is the variation of $C_{40}^{E n}$.

According to Eq. (18), $\eta$ can be obtained by fitting the efficiency curves from Fig. 17, namely the slope, as displayed in Fig. 18. It can be found from Fig. 18 that from S1 to $S 3$, the $\eta$ increases slowly from 0.027 to $0.067 \mu \mathrm{m} / \mu \mathrm{m}$, and then rises sharply to $0.183 \mu \mathrm{m} / \mu \mathrm{m}$ at $\mathrm{S} 4$, finally peaking to $0.495 \mu \mathrm{m} / \mu \mathrm{m}$ at $\mathrm{S} 5$. This indicates that the effect of the entry strip crown on the exit strip crown increases slowly in the first three stands, but surges in the last two stands.

\subsection{Effects of entry strip crown on strip flatness}

Figure 19 shows the strip flatness under various entry strip crowns from S1 to S5. From Fig. 19, it is clear that the flatness along the strip width direction changes dramatically with the variation of the entry strip crown. To quantify the variation of flatness, the flatness curves can be decomposed into $F l t_{2}$ and $F l t_{4}$ using Eq. (13), as shown in Fig. 20. From Figs. 19 and 20, it can be observed that when the $C_{40}^{E n}$ decreases from 116.4 to $-145.7 \mu \mathrm{m}$ at S1, the $F t_{2}$ decreases linearly from 0.08 to $-6.43 \mathrm{IU}$, while the $F t_{4}$ declines linearly from 0.54 to $0.27 \mathrm{IU}$. This means that the quadratic flatness changes from centre wave to edge wave, but the 

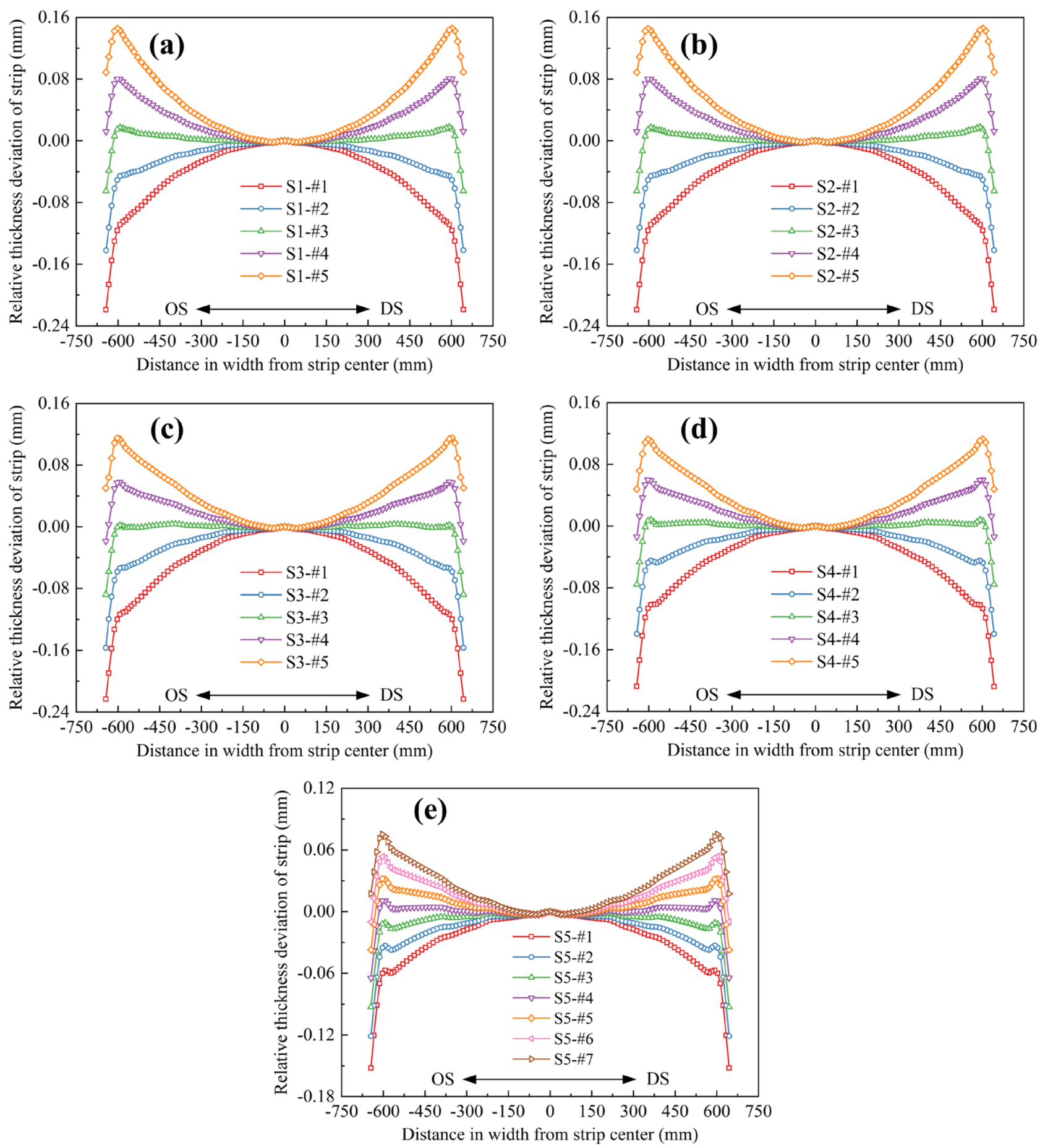

Fig. 15 Entry strip cross-section profiles: a S1 b S2 c S3 d S4 e S5

edge wave dominates. Meanwhile, the quarter wave occurs, with the decreasing intensity. The same trend can also be found at S2. As for S3, when the $C_{40}^{E n}$ decreases from 119.7 to $-115.1 \mu \mathrm{m}$, the $\mathrm{Flt}_{2}$ sees a linear decrease from 3.09 to $-9.35 \mathrm{IU}$, while the $\mathrm{Flt}_{4}$ remains stable at $0.07 \mathrm{IU}$. This suggests that the quadratic flatness changes from centre wave to edge wave, while the quarter wave appears and its magnitude changes little. By contrast, when the $C_{40}^{E n}$ decreases from 
Table 3 Entry strip crowns

\begin{tabular}{lrrrrr}
\hline Cases & \multicolumn{6}{l}{ Entry strip crown $C_{40}^{E n}(\mu \mathrm{m})$} \\
\cline { 2 - 6 } & \multicolumn{1}{c}{ S1 } & \multicolumn{1}{c}{ S2 } & \multicolumn{1}{c}{ S3 } & \multicolumn{1}{c}{ S4 } & \multicolumn{1}{c}{ S5 } \\
\hline$\# 1$ & 116.4 & 116.4 & 119.7 & 106.7 & 59.9 \\
$\# 2$ & 50.9 & 50.9 & 58.5 & 47.6 & 35.1 \\
$\# 3$ & -14.6 & -14.6 & 0.6 & -6.9 & 12.1 \\
$\# 4$ & -80.2 & -80.2 & -57.2 & -59.8 & -10.4 \\
$\# 5$ & -145.7 & -145.7 & -115.1 & -112.7 & -32.0 \\
$\# 6$ & - & - & - & - & -53.6 \\
$\# 7$ & - & - & - & - & -75.2 \\
\hline
\end{tabular}

106.7 to $-112.7 \mu \mathrm{m}$ at $\mathrm{S} 4$, there is a linear drop in $F l t_{2}$ from 6.78 to $-8.39 \mathrm{IU}$, as well as another linear drop in $F l t_{4}$ from 0.17 to $-0.32 \mathrm{IU}$. This indicates that the quadratic flatness changes from centre wave to edge wave, while the quartic flatness evolves from quarter wave to edge-centre coupled wave. Furthermore, the flatness of S5 shows a similar trend as that of S4.

To quantify the effect of entry strip crown on flatness, the efficiency factor $K_{F}$ is introduced by Eq. (19), which is determined by fitting the efficiency curves from Fig. 20.

$K_{F}=\frac{\Delta F l t}{\Delta C_{40}^{E n}}$

where $\Delta F l t$ is the variation of flatness.

Figure 21 compares the efficiency factor $K_{F}$ of $F l t_{2}$ and $\mathrm{Flt}_{4}$ from S1 to S5. As shown in Fig. 21, the $K_{F}$ of $F l t_{2}$ is much larger than that of $\mathrm{Flt}_{4}$. This demonstrates that the quadratic flatness dominates compared with the quartic flatness. What is more, from S1 to $\mathrm{S} 4$, the $K_{F}$ of $F l t_{2}$ increases steadily from 0.025 to $0.069 \mathrm{IU} / \mu \mathrm{m}$, and then decreases to $0.062 \mathrm{IU} / \mu \mathrm{m}$ at $\mathrm{S} 5$. In comparison, from $\mathrm{S} 1$ to S5, the $K_{F}$ of $\mathrm{Flt}_{4}$ shows an increase from 0.001 to $0.008 \mathrm{IU} / \mu \mathrm{m}$, except $\mathrm{S} 3$ where the $K_{F}$ of $\mathrm{Flt}_{4}$ is close to zero. This indicates that the effect of entry strip crown on quadratic flatness increases continuously from S1 to S4, and then decreases at S5. Comparatively, the effect of entry strip crown on quartic flatness exhibits an increasing trend from S1 to S5, except S3 in which the entry strip crown has little influence on quartic flatness.

\subsection{Effects of entry strip crown on the loaded roll gap profile}

In the strip rolling process, the strip shape is determined by the loaded roll gap profile. Specifically, the non-uniform loaded roll gap profile leads to the uneven deformation and residual stress of the strip, resulting in the non-desirable crown and flatness [27, 30]. Therefore, strip shape control methods, including various roll stack layouts, roll contours, and flatness actuators such as roll bending and roll shifting, are all used to regulate the loaded roll gap profile to be more uniform. Figure 22 compares the loaded roll gap profiles under various entry strip crowns from S1 to S5. It can be seen from Fig. 22 that the influence on the loaded roll gap is different from S1 to S5. Specifically, as for S1, S2, and $\mathrm{S} 3$, when the entry strip crown decreases from positive to negative, the crown of the loaded roll gap profile decreases slightly. In contrast, when the entry strip crown decreases from positive to negative at $\mathrm{S} 4$ and $\mathrm{S} 5$, the crown of the loaded roll gap profile shows an obvious decrease. More precisely, the $C_{40}$ of loaded roll gap profile at $\mathrm{S} 4$ drops significantly from 55.3 to $-19.5 \mu \mathrm{m}$ when the $C_{40}^{E n}$ decreases from 106.7 to $-112.7 \mu \mathrm{m}$, whereas the $C_{40}$ of loaded roll gap profile at S5 falls dramatically from 58.3 to $-75.0 \mu \mathrm{m}$ when the $C_{40}^{E n}$ decreases from 59.9 to $-75.2 \mu \mathrm{m}$. This indicates that the loaded roll gap profile shows high similarity with the entry strip cross-section profile at S4 and S5. Furthermore, the loaded roll gap profile agrees well with the exit strip cross-section profile (see Fig. 16) except for a little elastic recovery of the strip.

\subsection{Effects of entry strip crown on the elastic deformation of WR}

During the strip rolling process, the loaded roll gap profile is determined by the elastic deflection and flattening deformation of the roll stack. Figure 23 shows the deflection of WR axis under different entry strip crowns from $\mathrm{S} 1$ to S5. It can be observed that the deflection of WR axis shows an S-like shape, which accords with the CVC contour of IMR. Furthermore, the deflection of WR axis increases with the decrease in entry strip crowns from S1 to S5. This is because the average entry strip thickness increases with the decrease of the entry strip crown, leading to the larger plastic deformation of the strip, especially at the strip edge, consequently resulting in the larger elastic deflection of WR axis. More specifically, from S1 to $\mathrm{S} 3$, the deflection of WR axis is hill-like in shape along the strip width direction, thus forming the large crown of the loaded roll gap, causing the large exit strip crown (see Fig. 16a-c). In comparison, when it comes to S4 and S5, the deflection of WR axis distributes more uniformly along the strip width direction, so the crown of the loaded roll gap profile is relatively small, resulting in a small exit strip crown (see Fig. 16d, e).

Figure 24 compares the flattening deformation of WR between WR and strip under different entry strip crowns from S1 to S5. It can be seen from Fig. 24 that, from S1 

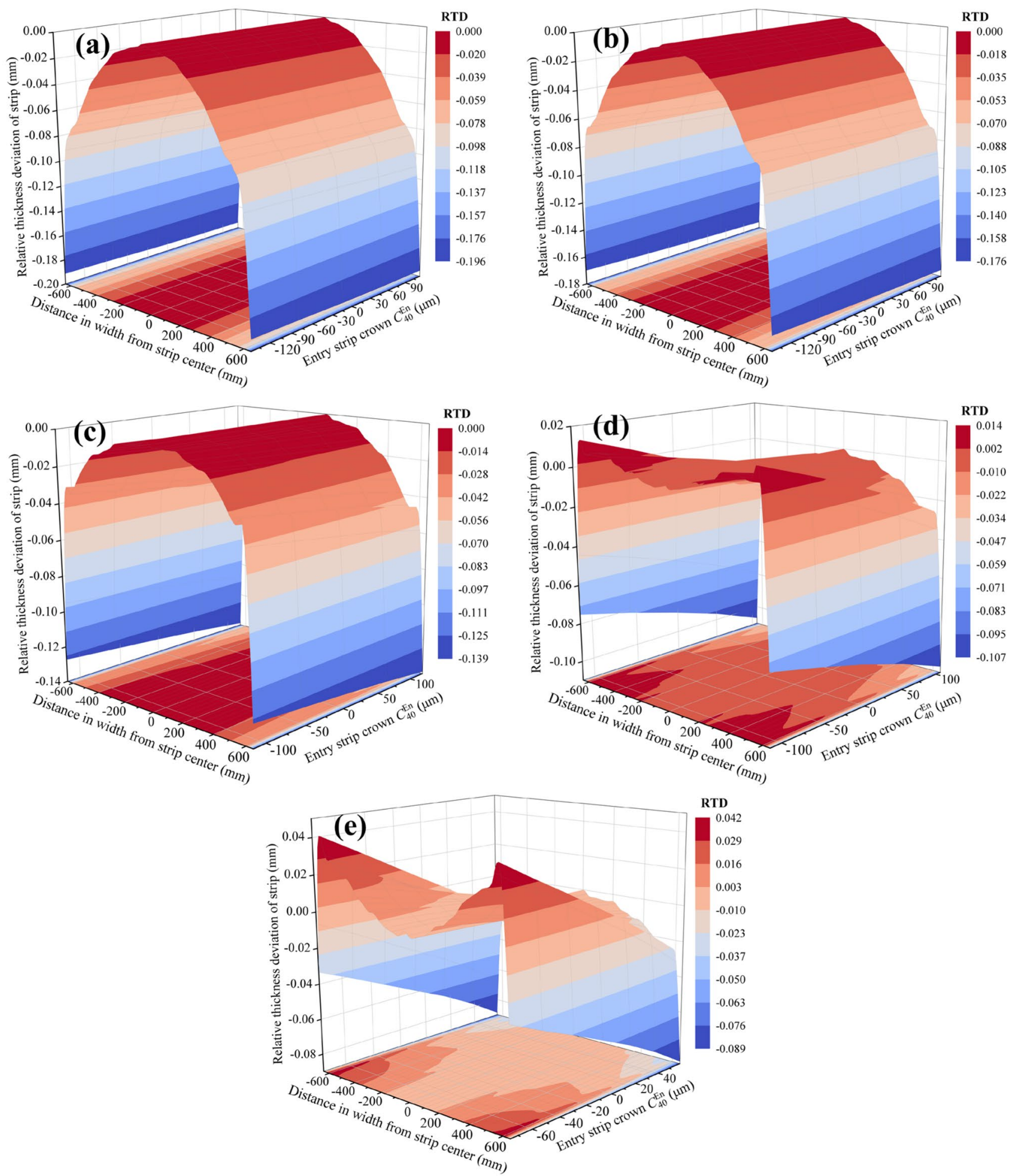

Fig. 16 RTD of strip under different entry strip crowns: a S1 b S2 c S3 d S4 e S5 


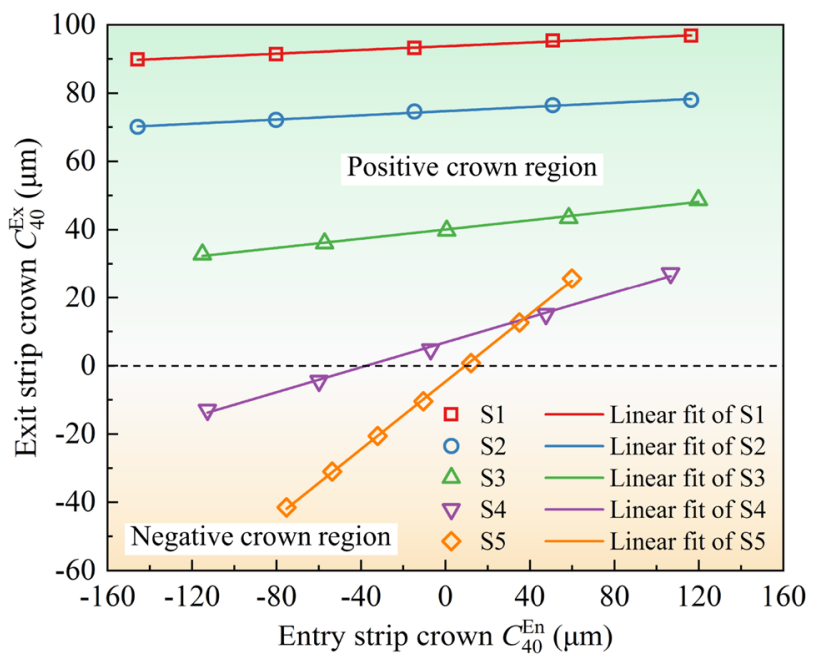

Fig. 17 The efficiency curves of entry strip crown on exit strip crown

to $\mathrm{S} 3$, the flattening deformation of WR changes little in the central strip region, whereas it increases slightly with the decrease in entry strip crown at the strip edge. This can be explained by that: on the one hand, the strip is easy to deform due to the low plastic rigidity of the strip [21]; on the other hand, the pass reduction ratio is large enough during the upstream stands (more than $30 \%$ ), so the influence of the entry strip crown on the total plastic deformation of the strip is comparatively small, and the plastic deformation only increases a little at the strip edge owing to an increase in strip thickness. These two aspects affect the flattening deformation of WR at the same time, so the entry strip crown exerts a slight effect on the flattening deformation of WR in the upstream stands. By contrast,

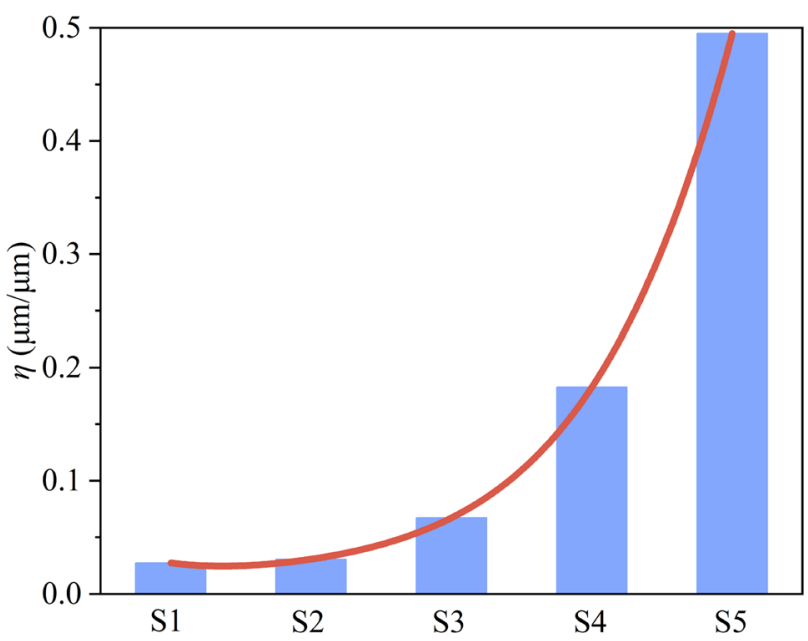

Fig. 18 The strip crown inheritance factor from S1 to S5 regarding S4 and S5, when the entry strip crown decreases from positive to negative, the flattening deformation of WR decreases in the central strip region, but increases significantly at the strip edge. This result can be explained by the fact that: first, the strip plastic rigidity is too large [21], causing the strip hard to deform; second, the pass reduction during the downstream stands is relatively small, especially for $\mathrm{S} 5$ only with the reduction of $0.057 \mathrm{~mm}$, and any small fluctuation of entry strip crown will have a significant influence on the plastic deformation of the strip. The above two aspects have a joint effect on the flattening deformation of WR. As a result, the entry strip crown has a significant effect on the flattening deformation of WR in the downstream stands, which is similar to the entry cross-section profile of the strip.

\subsection{The relationship between the strip crown inheritance factor and strip plastic rigidity}

From Fig. 18, it is clear that the strip crown inheritance factor shows an increasing trend from S1 to S5, which is consistent with the prior research [31]. This trend is similar to that of the strip plastic rigidity $Q$ calculated in our previous study [21], and the two variations (i.e. $Q$ and $\eta$ ) from $\mathrm{S} 1$ to $\mathrm{S} 5$ are compared in Fig. 25a. It can be seen from Fig. 25a that the strip crown inheritance factor agrees with the strip plastic rigidity. Given the stands from S1 to S5 are equipped with the same equipment, the mill rigidity at each stand remains almost the same. This indicates that the strip crown inheritance factor depends on the strip plastic rigidity that is influenced by the work hardening effect. Figure 25b displays the strip crown inheritance factor versus the strip plastic rigidity. It can be found from Fig. 25b that the strip crown inheritance factor increases nonlinearly with the strip plastic rigidity, which can be well fitted by an exponential function curve, expressed as Eq. (20). This affords the underlying mechanism of strip crown inheritance, and the qualitative relationship offers a valuable reference for optimising the strip crown inheritance mathematical model in the TCR process.

$\eta=0.88855-0.91753^{*} \exp \left(-1.49848 \mathrm{E}-5^{*} Q\right)$

where $Q$ denotes the strip plastic rigidity.

\subsection{The formation mechanism of strip shape under different entry strip crowns}

According to the analysis earlier, the formation mechanism of strip shape under different entry strip crowns can be obtained, as shown in Fig. 26. The whole tandem mill 

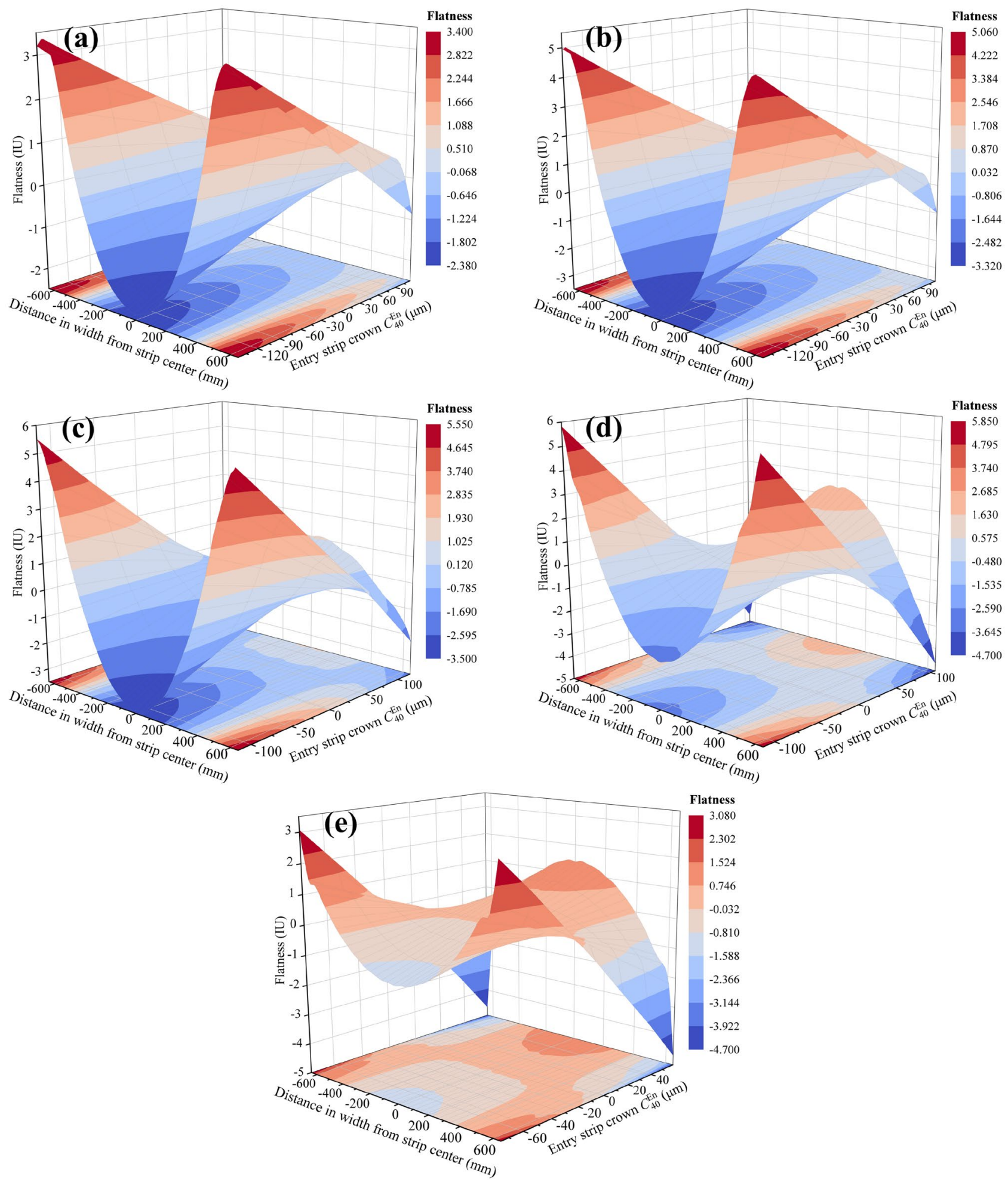

Fig. 19 Strip flatness under different rolling forces: a S1 b S2 c S3 d S4 e S5 


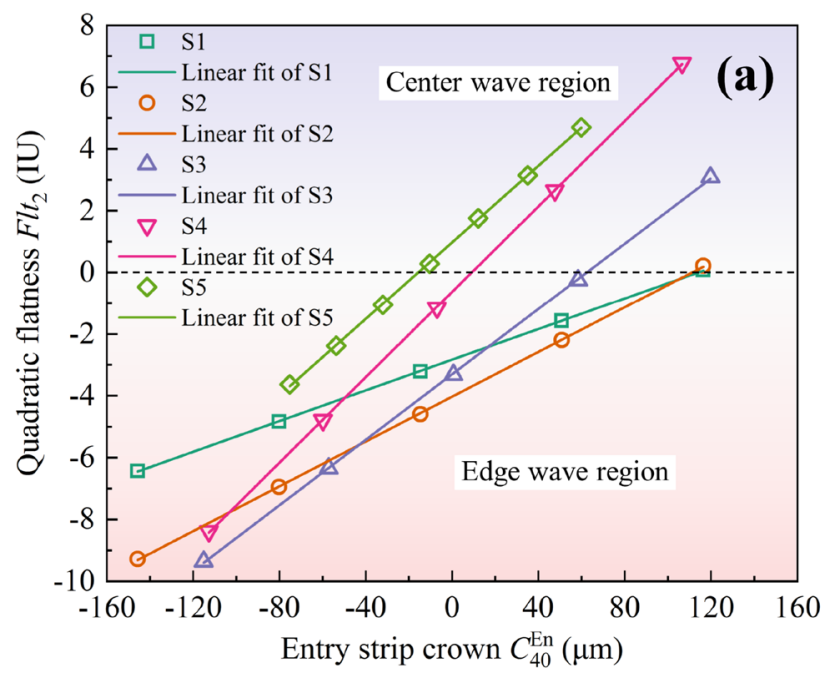

Fig. 20 The efficiency curves of entry strip crown on $\mathrm{Flt}_{2} \mathbf{a}$ and $\mathrm{Flt}_{4} \mathbf{b}$

can be divided into two parts: upstream stands (S1, S2, S3) and downstream stands (S4, S5). For the upstream stands featured with heavy reduction and low plastic rigidity, the loaded roll gap profile changes slightly under different entry strip crowns (Fig. 26, left panel), and thereby the exit strips all show a similar cross-section profile. This can be explained by the following factors: on the one hand, the range of the entry strip crown (see Table 3 ) is much smaller compared with the heavy pass reduction (see Table 2), which means that the deformation caused by the variation of entry strip crown accounts for a little in comparison to the total deformation; on the other hand, it is easy for the strip to deform due to its low plastic rigidity, implying that the thickness difference (see Fig. 15) caused by the variation of entry strip crown is easy to

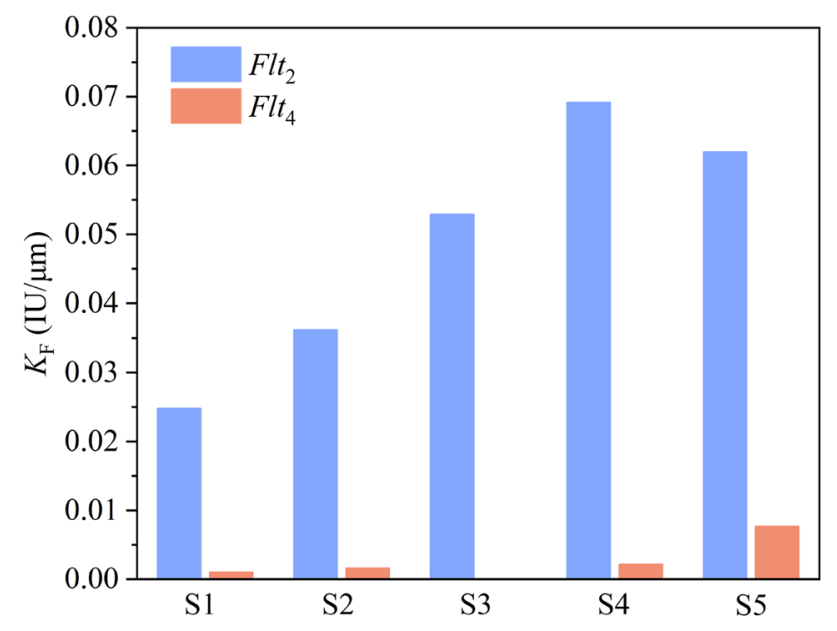

Fig. 21 The flatness efficiency factors of entry strip crown

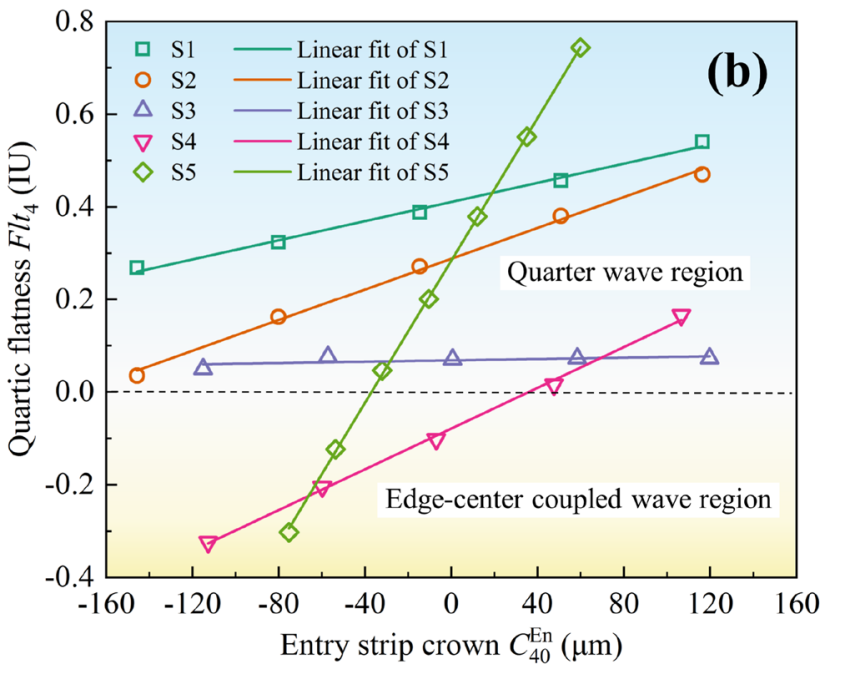

eliminate. Therefore, the entry strip crown has a limited effect on the exit strip crown (see Fig. 18). In other words, the upstream stands have a small strip inheritance factor. By contrast, the entry strip crown has a significant effect on the flatness due to the uneven elongation caused by the various compressed deformation. As shown in Fig. 26 (left panel), when the entry strip crown is negative, the edge wave dominates compared with the weak quarter wave, which is attributed to the large elongation of fibres at the strip edge due to the large compression at the strip edge. Moreover, the edge wave weakens while the quarter wave strengthens when the entry strip crown increases from negative to positive. This is owing to the larger elongation of fibres at the one-quarter position compared with that at the strip edge.

As for the downstream stands with light reduction and high plastic rigidity, it can be observed from Fig. 26 (right panel) that the loaded roll gap shows the similar profile to the entry strip cross-section. This can be explained by the fact that the plastic deformation introduced by the variation of the entry strip crown is close to the light reduction amount, especially for S5 (generally less than $0.1 \mathrm{~mm}$ ), and the strip is hard to deform owing to the high plastic rigidity, so the exit strip inherits much crown from the entry strip. For S5, the similarity between the entry strip crown and exit strip crown (namely the strip inheritance factor) is close to 0.5 (see Fig. 18). Furthermore, the flatness shows different characteristics under various entry strip crowns. Specifically, the edge-centre coupled wave appears when it comes to the negative entry strip crown, owing to the large elongation of fibres located at both the strip centre and edge. By contrast, the positive entry strip crown introduces the centre wave and quarter wave 

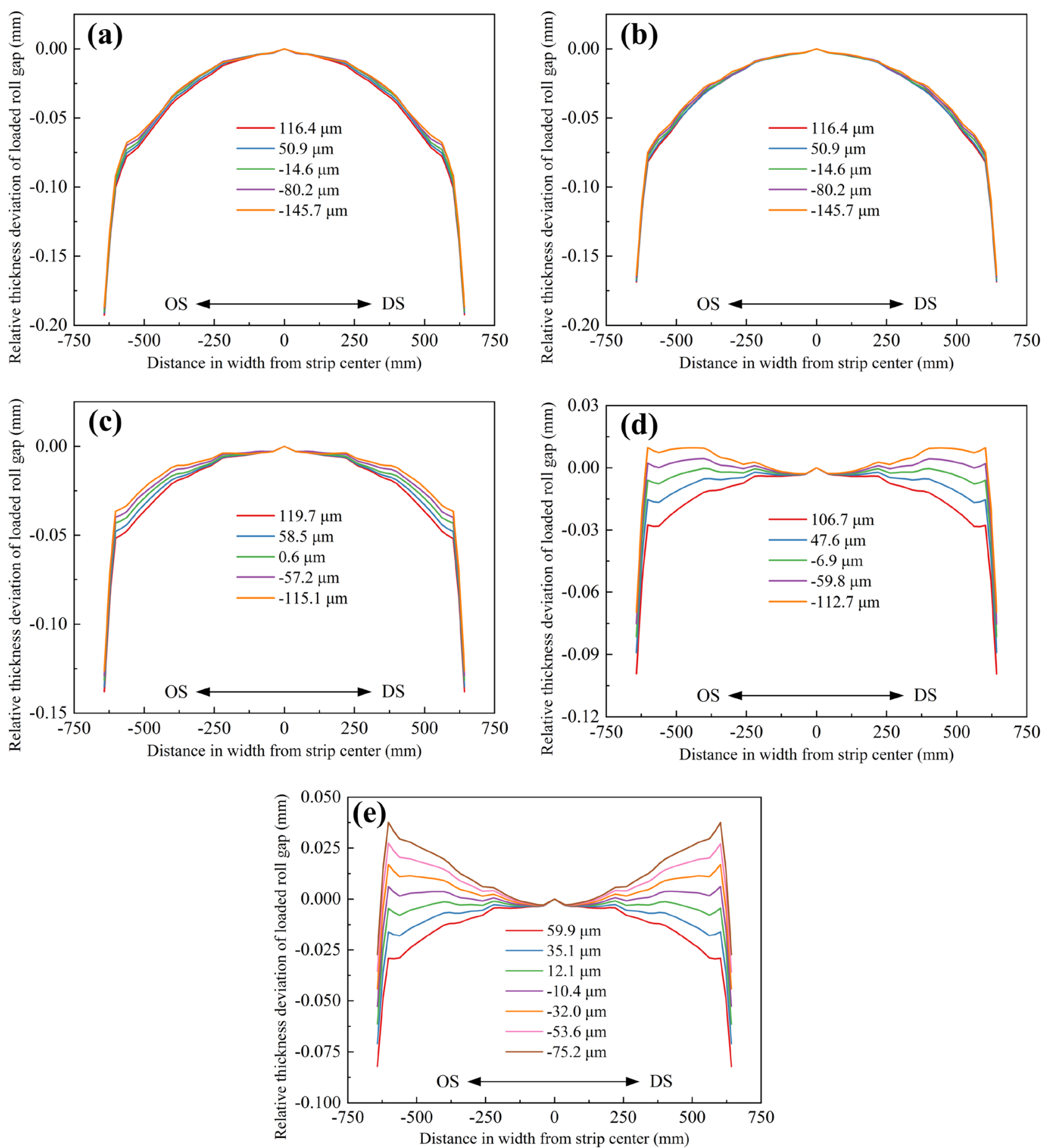

Fig. 22 The loaded roll gap profiles under different entry strip crowns: a S1 b S2 c S3 d S4 e S5 

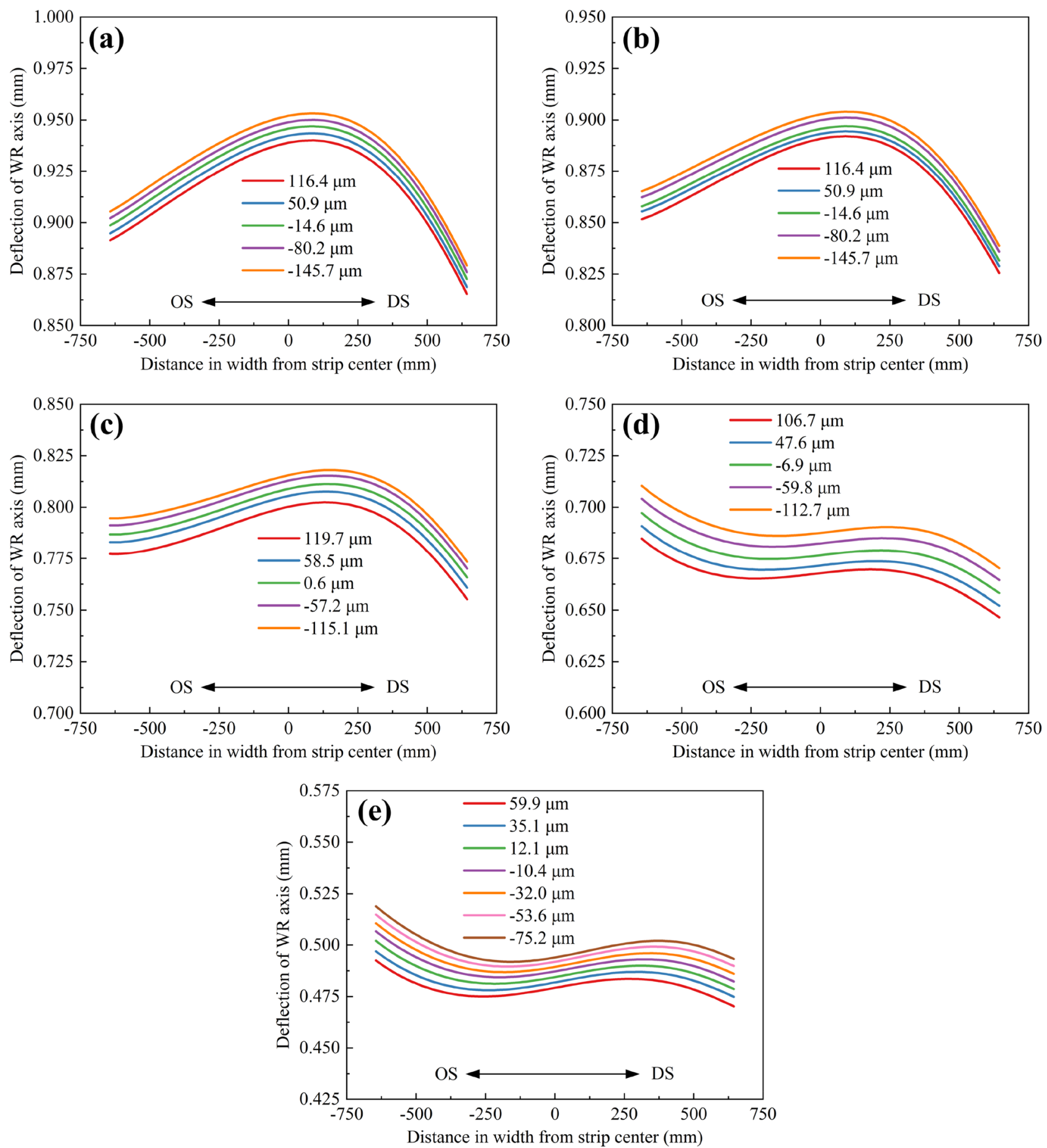

Fig. 23 Deflection of the WR axis: a S1 b S2 c S3 d S4 e S5 

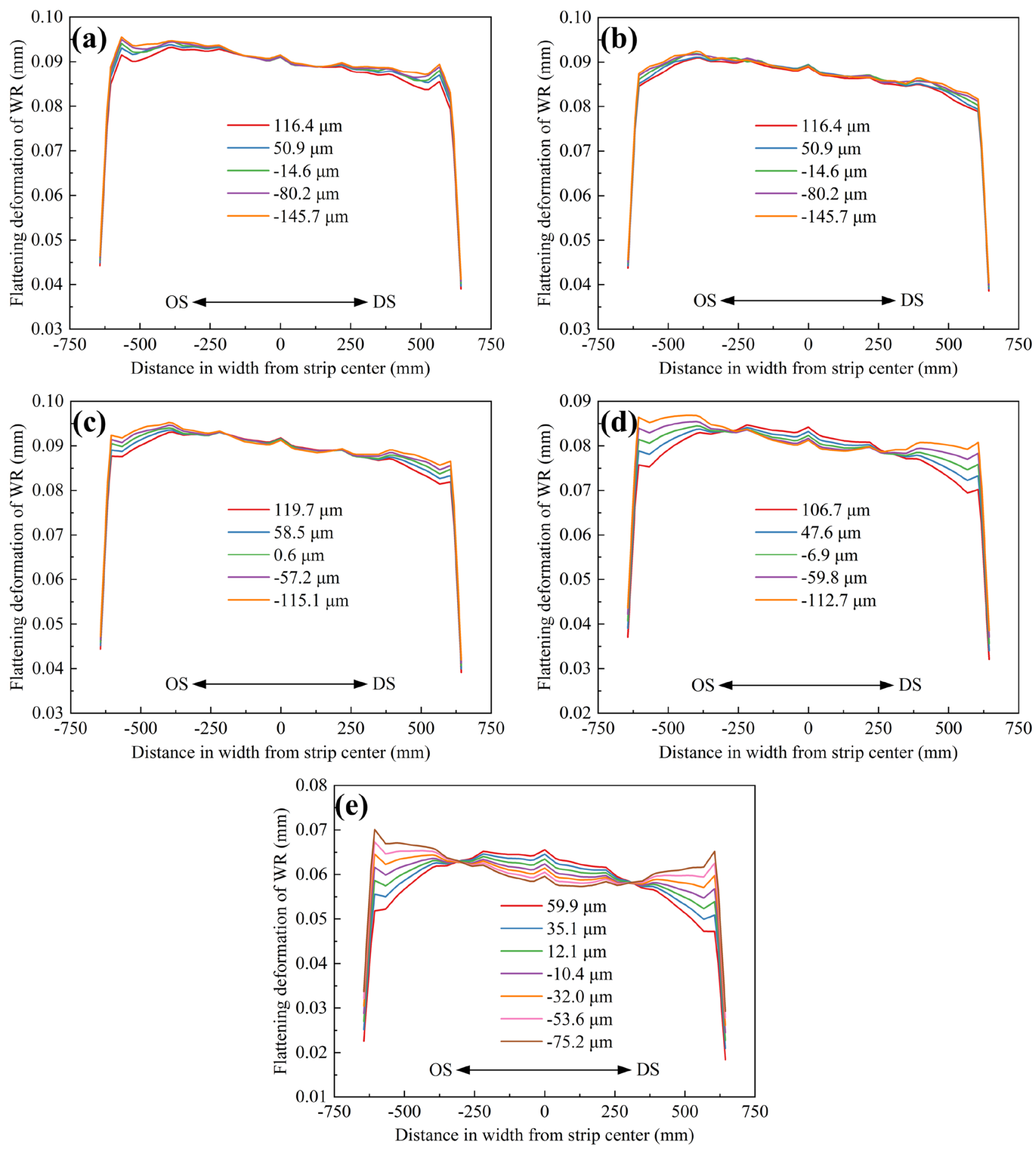

Fig. 24 Flattening deformation of WR between WR and strip: a S1 b S2 c S3 d S4 e S5 

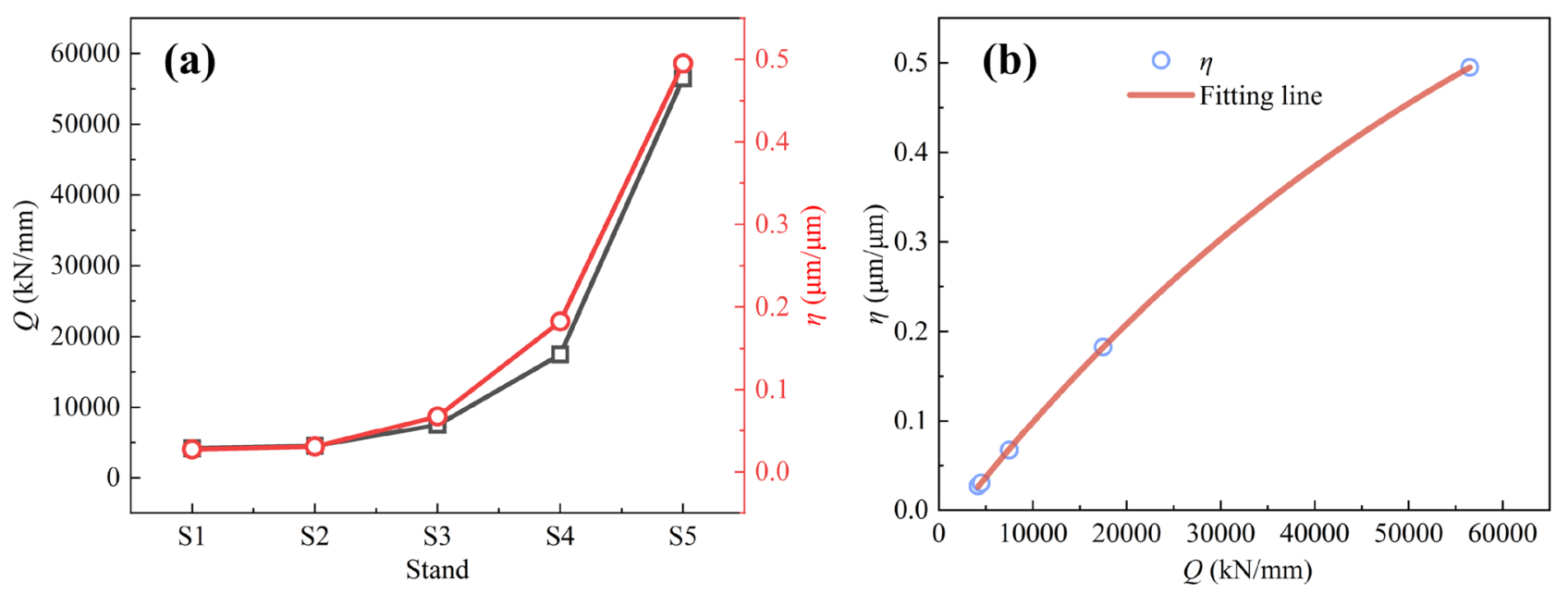

Fig. 25 a The values of $Q$ and $\eta$ from S1 to S5 $\mathbf{b}$ The curve of $\eta-Q$

because of the large elongation of fibres located at the strip centre and one-quarter position, while the flat entry strip brings in good flatness.

From the above mechanism analysis, the guidelines for strip shape control in the industry production line can be obtained below: first, the strip crown control should be mainly arranged within the upstream stands due to their small strip crown inheritance factor; second, to maintain a good flatness during the upstream stands, the incoming hot-rolled strip crown should be as small as possible, even close to the zero crown; third, to realise a good flatness in the downstream stands, the nearly-flat entry strip should be acquired from the upstream stands, so the flatness actuators like roll bending and roll shifting should be operated with the capacity to maintain the uniform loaded roll gap profile in the upstream stands, providing favourable strip crown condition to the downstream stands.

\subsection{The strip crown inheritance factor at stands S1 and S5}

To further verify the mechanism of strip crown inheritance proposed in Sect. 5.5, three different steel grades (780X, H420LA, and DC01) were selected for the incoming hot-rolled strip. The corresponding static deformation resistance curves are shown in Fig. 27. It can be found that the deformation resistance of $780 \mathrm{X}$ is much larger than that of H420LA, which is much larger than that of DC01. The corresponding strip crown inheritance factors

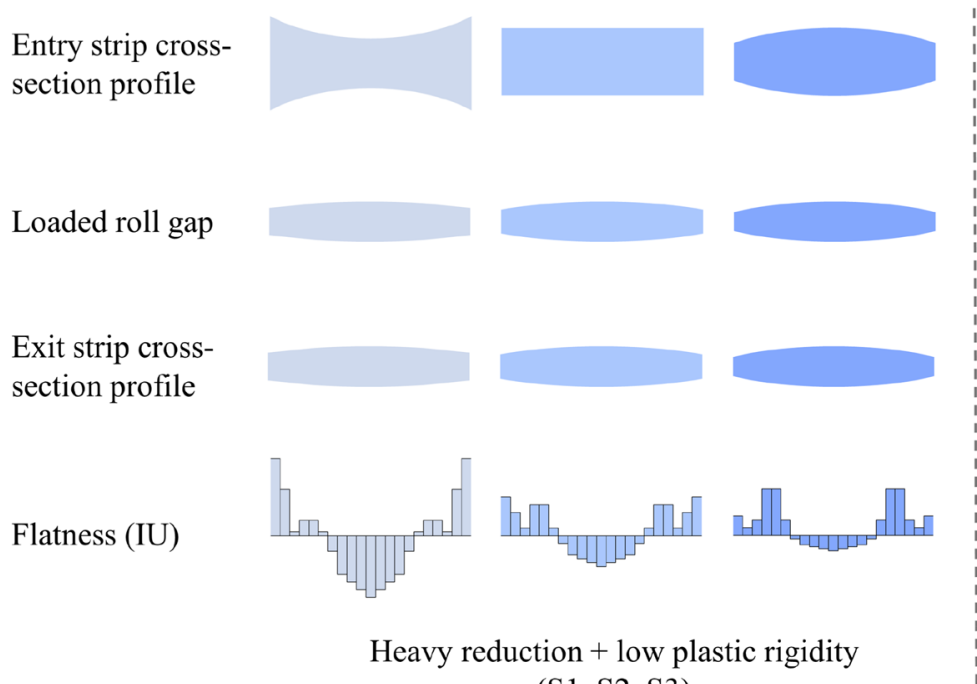
$(\mathrm{S} 1, \mathrm{~S} 2, \mathrm{~S} 3)$

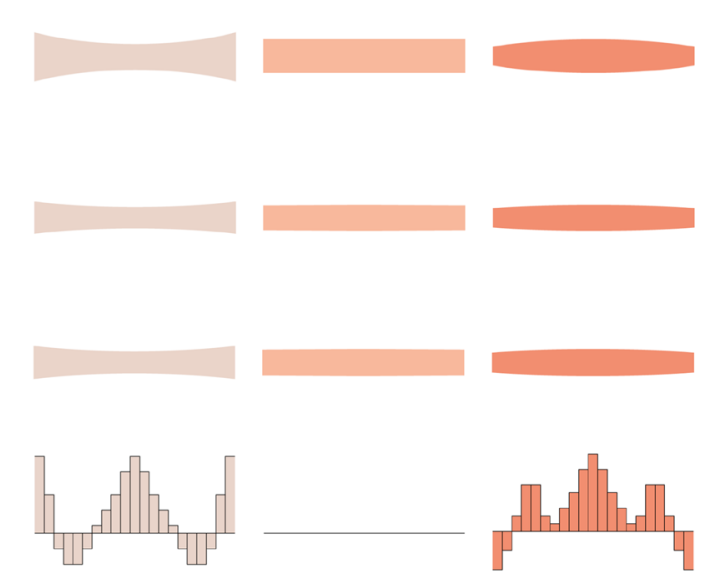

Light reduction + high plastic rigidity (S4, S5)

Fig. 26 The formation mechanism of strip shape under different entry strip crowns 


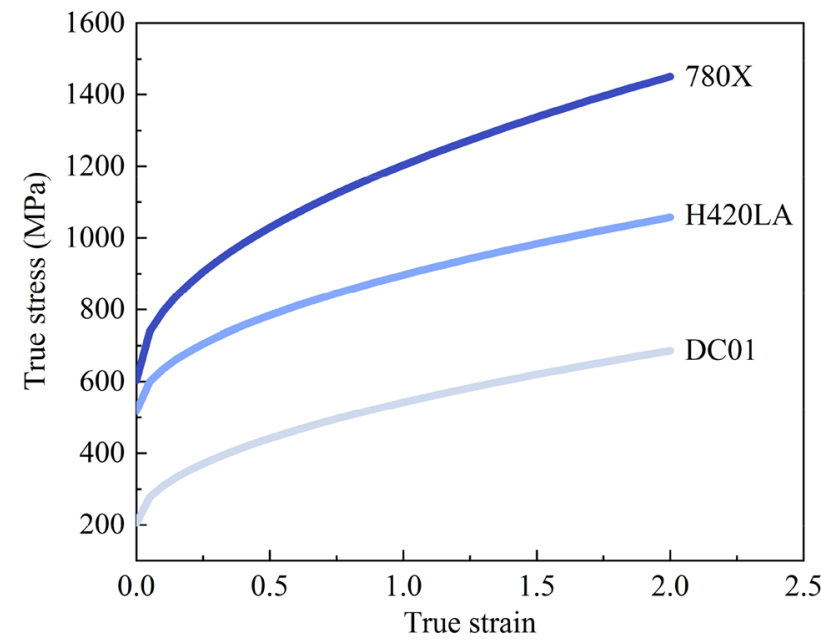

Fig. 27 The static deformation resistance curves of different steel grades

versus the strip plastic rigidity at S1 and S5 are presented in Fig. 28. It can be observed from Fig. 28 that the strip plastic rigidity and strip crown inheritance factor of 780X are significantly greater than those of H420LA, which are significantly greater than those of DC01. Furthermore, the strip crown inheritance factor shows a nonlinear increasing trend with the strip plastic rigidity, which can be well described by an exponential function curve, as expressed in Eqs. (21) and (22). This again demonstrates that the strip crown inheritance factor depends on the strip plastic rigidity, which depends on the strip deformation resistance. This suggests that the strip crown inheritance factor should be determined according to the strength levels of the strip.

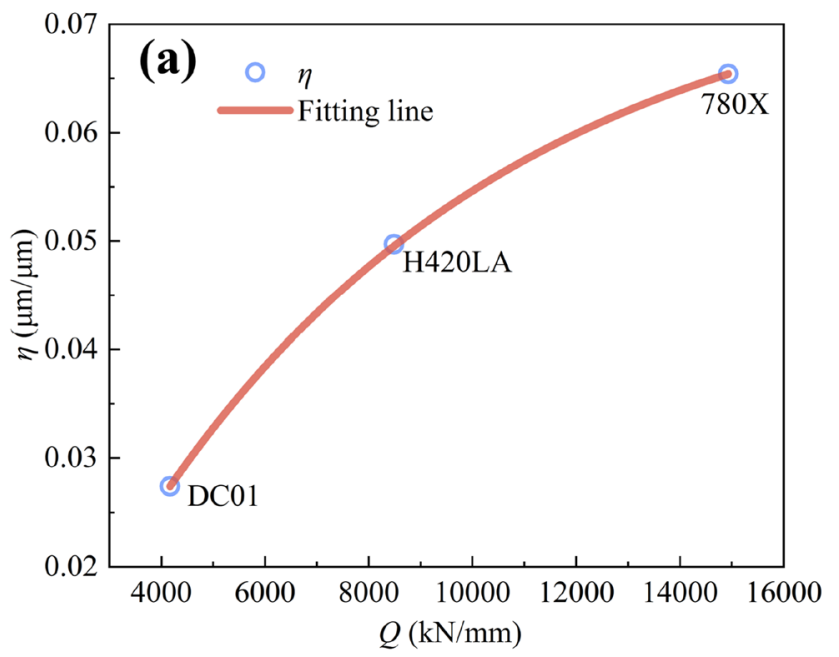

$\eta=0.07628-0.08749^{*} \exp \left(-1.39592 \mathrm{E}-4^{*} Q\right)$

$\eta=0.70695-0.30054^{*} \exp \left(6.18331 \mathrm{E}-6^{*} Q\right)$

From Fig. 28a, it can also be found that the strip crown inheritance factor is small at S1, less than 0.1 , even for high-strength steel 780X. This means that the stand S1 can be used to overcome the influence of the fluctuation for the incoming hot-rolled strip's crown and hardness on the crown and flatness of finished products [32]. By contrast, it can be observed from Fig. $28 \mathrm{~b}$ that the strip crown inheritance factor is relatively large at S5, especially for 780X, with the largest value of 0.671 . This suggests that the strip crown during stands S2-S4 should be kept in a good state, providing an appropriate condition for stand S5.

The small strip crown inheritance factor at $\mathrm{S} 1$ can be explained by that: it is known that the mill rigidity is determined by the whole mill, including the roll stack, mill house, and other auxiliary facilities; however, only the roll stack is taken into account in the present FE model, which leads to an increase in mill rigidity, as well as the roll gap rigidity. Consequently, this results in a decrease in the strip crown inheritance factor.

In this work, we mainly discuss the effects of entry strip crown on strip flatness. However, the entry strip edge drop or even wedge also exerts an effect on strip flatness. Abdelkhalek et al. [33] reported that the edge drop causes a slight decrease in wavelength during the cold thin strip rolling. The transverse thickness difference of the cold-rolled strip increases nonlinearly with the wedge of the hot-rolled strip [5]. Therefore, the quantitative study about the effects of entry strip edge drop or even wedge on strip flatness will be carried out in future work.

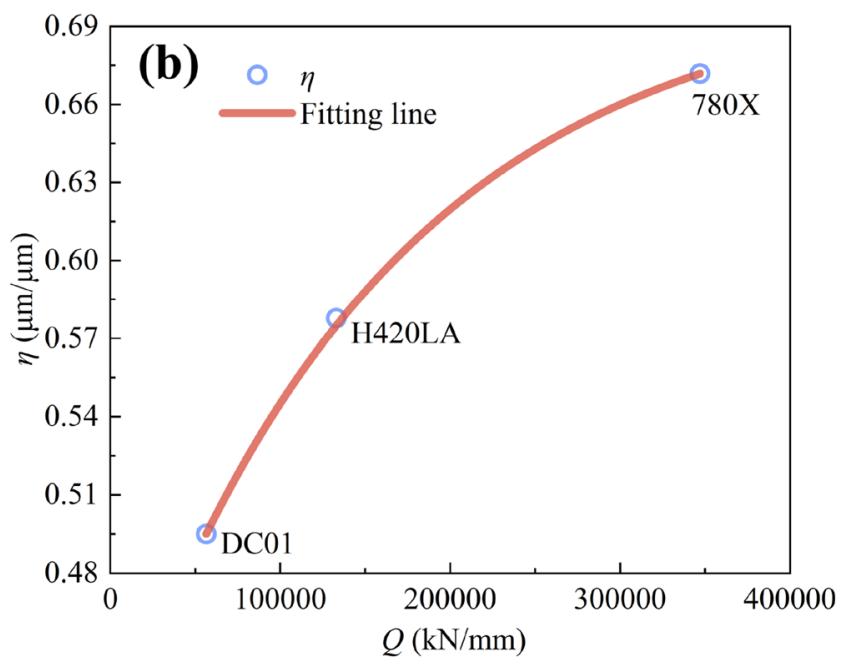

Fig. 28 The curve of $\eta-Q$ : a S1 b S5 


\section{Conclusions}

In this paper, on the basis of a 3D multi-stand elastic-plastic FE model for the TCR process considering the work hardening effect, the effects of the entry strip crown on exit strip crown and flatness at each stand were quantitatively analysed. The main conclusions can be drawn as follows:

1. The pass reduction and strip plastic rigidity have a combined effect on the evolution of strip crown and flatness under different entry strip crowns from S1 to S5. When the entry strip crown decreases from positive to negative, the exit strip crown decreases slightly in the upstream stands; while the exit strip crown undergoes a great decrease in the downstream stands. This is in accordance with the crown of the loaded roll gap profile.

2. With the variation of the entry strip crown, the quadratic flatness dominates compared with the quartic flatness from S1 to S5. Specifically, the influence of the entry strip crown on the quadratic flatness shows a steadily increasing trend from $\mathrm{S} 1$ to $\mathrm{S} 4$, although there is a little drop at $\mathrm{S} 5$, whereas the influence of the entry strip crown on the quartic flatness sees a gradual increase from $\mathrm{S} 1$ to $\mathrm{S} 5$, except $\mathrm{S} 3$ where the effect is close to zero.

3. When the entry strip crown decreases from positive to negative, the deflection of WR axis increases gradually; the flattening deformation of WR between WR and strip decreases in the strip centre, but increases at the strip edge.

4. Strip crown inheritance factor increases slowly from $\mathrm{S} 1$ to S3, but surges from S3 to S5. This is consistent with the trend of strip plastic rigidity. It demonstrates that the strip crown inheritance factor depends on the strip plastic rigidity. Furthermore, the strip crown inheritance factor increases with the strip's deformation resistance at both $\mathrm{S} 1$ and $\mathrm{S} 5$.

This work not only lays a solid foundation for future studies on strip shape inheritance, but also provides useful guidelines for improving the strip shape inheritance preset model and online strip shape control.

Author contribution Lianjie Li: conceptualization, formal analysis, investigation, methodology, writing - original draft. Haibo Xie: writing - review and editing. Tianwu Liu: validation, investigation. Mingshuai Huo: data processing. Xing sheng Li: offer assistance for subroutine development and calculation. Xu Liu: validation. Enrui Wang: data curation, validation. Jianxin Li: investigation, supervision. Hongqiang Liu: investigation. Li Sun: resources, investigation. Zhengyi Jiang: writing - review and editing, supervision, project administration.

Funding Open Access funding enabled and organized by CAUL and its Member Institutions. This work was funded by the HBIS Group in China with project No. 333002572.
Data availability The data are available from the corresponding author upon reasonable request.

Code availability The calculation was performed based on the MSC Marc software.

\section{Declarations}

Ethics approval Not applicable.

Consent to participate Not applicable.

Consent for publication Not applicable.

Conflict of interest The authors declare no competing interests.

Open Access This article is licensed under a Creative Commons Attribution 4.0 International License, which permits use, sharing, adaptation, distribution and reproduction in any medium or format, as long as you give appropriate credit to the original author(s) and the source, provide a link to the Creative Commons licence, and indicate if changes were made. The images or other third party material in this article are included in the article's Creative Commons licence, unless indicated otherwise in a credit line to the material. If material is not included in the article's Creative Commons licence and your intended use is not permitted by statutory regulation or exceeds the permitted use, you will need to obtain permission directly from the copyright holder. To view a copy of this licence, visit http://creativecommons.org/licenses/by/4.0/.

\section{References}

1. Guo RM (1988) Cascade effect of crown and shape control devices in tandem rolling mills. Iron and Steel Technology 65:29-38

2. Park HD, Kim IJ, Yi JJ et al (1994) Effect of the hot-coil profile on the flatness and profile of cold-rolled strip. J Mater Process Technol 41:349-360

3. Zhang Y, Yang Q, Wang X et al (2010) Analysis of cold-rolled strip profile in UCM mill by finite element method. Key Eng Mater 443:21-26

4. Yu HL, Liu XH, Lee GT (2007) Contact element method with two relative coordinates and its application to prediction of strip profile of a Sendzimir mill. ISIJ Int 47:996-1005

5. Ma XB, Wang DC, Liu HM et al (2018) Influence of profile indicators of hot-rolled strip on transverse thickness difference of cold-rolled silicon steel. Metall Res Technol 116(105)

6. Wang DC, Xu YH, Zhang TY et al (2021) Quantitative study on the relationship between the transverse thickness difference of cold-rolled silicon strip and incoming section profile based on the mechanism-intelligent model. Metall Res Technol 118:303

7. Zhou SX, Plociennik C, Zhong J (1998) Application of 2-dimensional FEM to predict the thickness profile in 4-high mills. Steel Res 69:482-488

8. Jiang ZY, Tieu AK, Zhang XM et al (2003) Finite element simulation of cold rolling of thin strip. J Mater Process Technol 140:542-547

9. Jiang ZY, Tieu AK (2003) Modelling of thin strip cold rolling with friction variation by a 3-D finite element method. JSME Int J Ser A 46:218-223

10. Jiang ZY, Tieu AK (2004) A 3-D finite element method analysis of cold rolling of thin strip with friction variation. Tribol Int 37:185-191 
11. Sun JN, Du FS, Li XT (2008) FEM simulation of the roll deformation of six-high CVC mill in cold strip rolling. In: Zhu J (ed) 2008 International Workshop on Modelling. Simulation and Optimization, Hong Kong, pp 412-415

12. Aljabri A, Jiang ZY, Wei DB (2014) Finite element analysis of thin strip profile in asymmetric cold rolling considering work roll crossing and shifting. Adv Mat Res 1061-1062:515-521

13. Wang QL, Sun J, Liu YM et al (2017) Analysis of symmetrical flatness actuator efficiencies for UCM cold rolling mill by $3 \mathrm{D}$ elastic-plastic FEM. Int J Adv Manuf Technol 92:1371-1389

14. Wang QL, Sun J, Li X et al (2018) Numerical and experimental analysis of strip cross-directional control and flatness prediction for UCM cold rolling mill. J Manuf Process 34:637-649

15. Wang QL, Li X, Hu YJ et al (2018) Numerical analysis of intermediate roll shifting-induced rigidity characteristics of UCM cold rolling mill. Steel Res Int 89(1700454)

16. Cao JG, Chai XT, Li YL et al (2018) Integrated design of roll contours for strip edge drop and crown control in tandem cold rolling mills. J Mater Process Technol 252:432-439

17. Zamanian A, Nam SY, Hwang SM (2019) A new mill design for the production of a strip with zero strip crown. Steel Res Int 90:1-8

18. Wang XC, Yang Q, He HN et al (2020) Effect of work roll shifting control on edge drop for 6-hi tandem cold mills based on finite element method model. Int $\mathbf{J}$ Adv Manuf Technol 107:2497-2511

19. Wang QL, Li X, Sun J et al (2021) Mathematical and numerical analysis of cross-directional control for SmartCrown rolls in strip mill. J Manuf Process 69:451-472

20. Linghu KZ, Jiang ZY, Zhao JW et al (2014) 3D FEM analysis of strip shape during multi-pass rolling in a 6-high CVC cold rolling mill. Int J Adv Manuf Technol 74:1733-1745

21. Li LJ, Xie HB, Liu TW et al (2021) Effects of rolling force on strip shape during tandem cold rolling using a novel multistand finite element model. Steel Res Int 2100359

22. Liu XH, Hu XL, Du LX (2007) Calculation model of rolling parameters and its application. Chemical Industry Press, Beijing

23. Marc (2017) User's manual volume A: theory and user information. MSC Software Corporation, USA

24. Zienkiewicz OC, Taylor RL, Zhu J (2013) The finite element method: its basis and fundamentals. Butterworth-Heinemann, United Kingdom
25. Bald W, Beisemann G, Feldmann H et al (1987) Continuously variable crown (CVC) rolling. Iron and Steel Engineer 64:32-41

26. Zhang SH, Deng L, Tian WH et al (2022) Deduction of a quadratic velocity field and its application to rolling force of extra-thick plate. Comput Math Appl 109:58-73

27. Wang QL, Sun J, Li X et al (2020) Analysis of lateral metal flow-induced flatness deviations of rolled steel strip: mathematical modeling and simulation experiments. Appl Math Model 77:289-308

28. Grimble M, Fotakis J (1982) The design of strip shape control systems for Sendzimir mills. IEEE Trans Autom Control 27:656-666

29. Judin M, Nylander J, Larkiola J et al (2011) Quality parameters defined by Chebyshev polynomials in cold rolling process chain. In: Menary G (ed) The 14th International ESAFORM Conference on Material Forming: ESAFORM 2011. American Institute of Physics, Belfast, pp 368-373

30. Zhou ZQ, Lam Y, Thomson PF et al (2007) Numerical analysis of the flatness of thin, rolled steel strip on the runout table. Proc Inst Mech Eng B J Eng Manuf 221:241-254

31. Yang GH, Zhang J, Cao JG et al (2015) Strip shape control and inspection in tandem cold rolling. Metallurgical Industry Press, Beijing

32. Cao JG, Jiang J, Qiu L et al (2019) High precision integrated profile and flatness control for new-generation high-tech wide strip cold rolling mills. J Cent South Univ 50:1584-1591

33. Abdelkhalek S, Nakhoul R, Zahrouni H et al (2012) Applications of advanced models to prediction of flatness defects in cold rolling of thin strips. In: Tieu AK (Ed) 15th International Conference on Advances in Materials and Processing Technologies-AMPT 2012, Wollongong, Australia

Publisher's Note Springer Nature remains neutral with regard to jurisdictional claims in published maps and institutional affiliations. 